\title{
Behavior of silver nanoparticles and ions in food simulants and low fat cow milk under migration conditions
}

Jokar, Maryam; Correia, Manuel; Löschner, Katrin

Published in:
Food Control

Link to article, DOI:

10.1016/j.foodcont.2018.01.023

Publication date:

2018

Document Version

Peer reviewed version

Link back to DTU Orbit

Citation (APA):

Jokar, M., Correia, M., \& Löschner, K. (2018). Behavior of silver nanoparticles and ions in food simulants and low fat cow milk under migration conditions. Food Control, 89, 77-85.

https://doi.org/10.1016/j.foodcont.2018.01.023

\section{General rights}

Copyright and moral rights for the publications made accessible in the public portal are retained by the authors and/or other copyright owners and it is a condition of accessing publications that users recognise and abide by the legal requirements associated with these rights.

- Users may download and print one copy of any publication from the public portal for the purpose of private study or research.

- You may not further distribute the material or use it for any profit-making activity or commercial gain

- You may freely distribute the URL identifying the publication in the public portal

If you believe that this document breaches copyright please contact us providing details, and we will remove access to the work immediately and investigate your claim. 
This is a post-peer-review, pre-copyedit version of an article published in Food Chemistry. The final authenticated version is available online at: https://doi.org/10.1016/j.foodcont.2018.01.023.

Behavior of Silver Nanoparticles and Ions in Food Simulants and Low Fat Cow Milk under Migration Conditions

\section{Maryam Jokar*, Manuel Correia, Katrin Loeschner*}

Research Group for Nano-Bio Science, Division of Food Technology, National Food Institute, Technical University of Denmark, Lyngby, Denmark

*corresponding authors

Maryam Jokar

Address: Division of Food Technology, National Food Institute, Technical University of Denmark, Kemitorvet, Building 201, DK-2800 Kgs Lyngby, Denmark

Email:marjok@food.dtu.dk

Phone: +45 35887466

Fax: +4535887448

Katrin Loeschner

Address: Division of Food Technology, National Food Institute, Technical University of Denmark, Kemitorvet, Building 201, DK-2800 Kgs Lyngby, Denmark

Email: kals@food.dtu.dk

Phone: +4535887029

Fax: +4535887448 


\title{
Highlights
}

- Silver nanoparticles (AgNPs) were characterized in aqueous and fatty food simulants and milk using inductively coupled plasma-mass spectrometry in single particle mode (spICP-MS)

- AgNPs dissolve in all food/food simulants after long incubation (10 days) at $40^{\circ} \mathrm{C}$ but to a lesser extent in ethanolic simulants and milk

- Formation of AgNPs from silver ions is shown to be unlikely at typical migration concentrations (< $\left.20 \mu \mathrm{g} \mathrm{L}^{-1}\right)$

\begin{abstract}
Research on the potential migration of nanoparticles (NPs) from nano-based food contact materials (FCMs) has often reached inconsistency in previous studies. Conventional food simulants and traditional migration tests, which are established for small molecules, have been used for studying the potential migration of NPs from nano-based FCMs. The suitability of conventional food simulants and migration tests was investigated by studying the behavior of $40 \mathrm{~nm}$ polyethylene glycol (PEG) coated AgNPs and silver ions in food simulants ( $10 \%$ ethanol, $20 \%$ ethanol, $50 \%$ ethanol, $3 \%$ acetic acid, olive oil) under migration conditions. Particle mass and number concentrations, ionic concentration and particle size distributions were determined by single particle inductively coupled plasma-mass spectrometry (spICP-MS) before and after incubation for 4 hours or 10 days at $40^{\circ} \mathrm{C}$. In agreement with similar studies, $50 \%$ ethanol preserved the AgNPs, while acetic acid induced dissolution of AgNPs. Dissolution of the PEG-AgNPs obeyed pseudofirst-order reaction kinetics. PEG-AgNPs showed similar behavior in low fat cow milk during storage at $4^{\circ} \mathrm{C}$ for 5 days as in the corresponding food simulant, $50 \%$ ethanol. Addition of sodium chloride to ultrapure water led to enhanced dissolution. The potential reduction of silver ions to NPs in food simulants, low fat milk and in alkaline conditions in the presence of reducing agents was studied. Based on the obtained results, it is unlikely that AgNPs are formed from $\mathrm{Ag}$ ions at the low concentration which are typically observed for the migration of Ag from polymeric FCMs.
\end{abstract}

Key Words: Migration, Food Simulants, sp-ICPMS, Silver nanoparticles 


\section{Introduction}

Nanomaterials (NM) can be used to improve the functional properties of food packaging materials such as barrier, mechanical and thermal characteristics, and to provide antimicrobial activity. The application of NMs may lead to an increase of the shelf life of food products, improve food safety, reduce food waste and subsequently contribute positively to the global food security (Hannon, Cummins, et al. 2015). On the other hand, the use of NMs in food contact materials (FCMs) poses challenges in terms of regulation and potential health risks, that should be considered. Studying the migration of nanoparticles (NPs) from nanobased FCMs is crucial due to potential health risks of the migrating NPs, which is related to their small size, different physicochemical properties and potentially higher bioavailability due to increased and faster permit thorough natural biological barriers (Noonan et al. 2014). According to the European Food Safety Authority's (EFSA) Scientific Opinion from 2009 (EFSA 2009), the potential risk arising from nanoscience and nanotechnology in food and FCMs has to be clarified, and the toxicology of engineered NMs cannot fully be inferred by extrapolation from data on their equivalent non-nano forms.

The literature has shown inconsistency about the migration of NPs from nano-based FCMs. The open questions regarding the migration of NPs from nano-based FCMs has been reviewed in our previous study (Jokar et al. 2016). One of the challenges relates to the suitability of conventional food simulants and migration tests conditions for nano-based FCMs, which was discussed extensively in question number 4 in our review paper. Standard food simulants are used in migration test to simplify food matrices and represent different categories of foods, such as hydrophilic, acidic, alcoholic and lipophilic foods. Standard food simulants were established for molecular substances for which the chemical and physical structure remains stable during migration testing and where different food simulants influence only the migration rates of the substance. In contrast, the physicochemical characteristics of NPs (which are critical from a safety point of view), such as shape, size, agglomeration state, surface charge and chemical composition, may vary in different food simulants. In contrast to molecules, NPs can undergo transformation processes, like dissolution, chemical (surface) modification, agglomeration, and aggregation which lead to changes of their chemical composition, shape, and size. These processes are influenced by migration conditions (temperature and time) and food simulants properties ( $\mathrm{pH}$, ionic strength, and chemical composition).

The migration of Ag nanoparticles (AgNPs) from polymer-based FCMs has been studied extensively in recent years which can be explained by the relatively frequent use of Ag (as antimicrobial agent) in FCMs and, on the other, with the fact that $\mathrm{Ag}$ can be relatively easily analysed by spICP-MS and electron microscopy (Jokar et al. 2016). Several studies evidenced migration of AgNPs from FCMs into food simulants (von Goetz et al. 2013; Echegoyen \& Nerín 2013; Artiaga et al. 2015; Hannon, Kerry, et al. 2015; Mackevica et al. 2016; Ramos et al. 2016). The secondary formation of AgNPs from migrated ions by chemical reduction has been postulated (Noonan et al. 2014; Mackevica et al. 2016).

AgNPs are very far from chemically inert, and once released, multiple chemical and physical transformations such as aggregation, oxidation, dissolution and sulfidation are expected to occur. Similar to environmental transformation of AgNPs, where chemical transformation influences their characteristics and alters their transport, fate and toxicity (Levard et al. 2012), transformation of NPs in food can influence the behaviour and fate of AgNPs in the gastrointestinal tract (EFSA 2009).

Inductively coupled plasma-mass spectrometry in single particle mode (spICP-MS) has proven to be a powerful technique for detection and characterization of aqueous solutions of metal containing NPs. This method is based on the generation of discrete signals of ions that arise from single particles continuously introduced into the ICP-MS (Montaño et al. 2016). The major analytical challenges in the case of migrations studies are the typically low concentrations of migrating NPs and the likelihood of artefacts during sample preparation (Hassellöv et al. 2008; Tiede et al. 2008). The advantages of spICP-MS for migration studies are: i) the great sensitivity that allows the detection of NPs at low mass concentrations (ng L ${ }^{-1}$ range), ii) the ability to quantify the ratio between ions and NPs of a certain element in migration solutions, and iii) the possibility of direct analysis without the need for sample preparation or after simple dilution with ultrapure water. 
There is insufficient data in the literature about the behavior of migrating NPs in food and in food simulants during migration test. Ntim et al. studied the effects of aqueous food simulants (water, $10 \%$ ethanol, $3 \%$ acetic acid) during 4 hour incubation at $100^{\circ} \mathrm{C}$ on $60 \mathrm{~nm}$ AgNPs coated with polyvinylpyrrolidone (PVP) by asymmetric flow field-flow fractionation, ultrafiltration, electron microscopy and spICP-MS (Ntim et al. 2016). The testing conditions were chosen to simulate the reheating of ready-prepared foods (in frozen and refrigerated storage) in the container at the time of the use. AgNPs were preserved in the presence of water and $10 \%$ ethanol but dissolved in $3 \%$ acetic acid. In migration studies of commercially available food storage containers, similar size distributions of AgNPs in ultrapure water and ethanol were observed by spICP-MS, but much larger particles were detected in 3\% acetic acid (Mackevica et al. 2016). For one storage container, dissolution of AgNPs in acetic acid was described. It was concluded that acetic acid could cause both, aggregation and dissolution of AgNPs. So far, no study investigated the likelihood of NP formation from migrating ions in food/food simulants. The objective of this paper was to investigate the effects of ultrapure water with and without added sodium chloride, a wider range of food simulants (10\% ethanol, $20 \%$ ethanol, $50 \%$ ethanol , $3 \%$ acetic acid, olive oil) and low fat cow milk, as an example of a complex food matrix, on AgNPs and silver ions at times (4 hours and 10 days) and temperature $\left(40^{\circ} \mathrm{C}\right.$ ) relevant for migration testing.

\section{Materials and methods}

\subsection{Materials}

Ultrapure water was obtained from a Millipore Element apparatus (Millipore, Milford, MA, USA) and used throughout the work. NIST gold nanoparticle (AuNPs) reference material, RM 8013, nominal diameter 60 $\mathrm{nm}$, was purchased from the NIST (Gaithersburg, MD, USA). The $1000 \mu \mathrm{g} \mathrm{mL}^{-1}$ standard solutions of silver $(\mathrm{Ag})$, gold $(\mathrm{Au})$, and rhodium (Rh) in $4 \% \mathrm{HNO}_{3}$ (ICP-MS grade) were purchased from SCP Science (Quebec, Canada). Plasma-pure acids of $\mathrm{HCl}(34-37 \%)$ and $\mathrm{HNO}_{3}(67-69 \%)$ were purchased from SCP Science (Quebec, Canada). Ethanol ( $\left.96 \% \mathrm{v} / \mathrm{v}, 0.81 \mathrm{~kg} \mathrm{~L}^{-1}\right)$ was purchased from CCS Healthcare AB (Borlange, Sweden). Methanol (HPLC-grade) was purchased from Rathburn Chemicals Ltd (United Kingdom). Silver nitrate $\left(\mathrm{AgNO}_{3}\right)$ and polyvinylpyrrolidone (PVP) with a molecular weight of $10000 \mathrm{~g} / \mathrm{mol}$ were purchased from Sigma Aldrich (USA). Sodium hydroxide $(\mathrm{NaOH})$ pellets, sodium chloride ( $\mathrm{NaCl}$ ) with analytical grade, glacial acetic acid $\left(\mathrm{CH}_{3} \mathrm{COOH}\right)$, and Triton X-100 were purchased from Merck (Darmstadt, Germany). Extra virgin olive oil was purchased in a Danish supermarket from San Felipe, Aceites Del Sur, S.L. (Madrid, Spain). Polyethylene glycol (PEG) stabilized silver NPs (PEG-AgNPs) and citrate stabilized silver NPs (Citrate-AgNPs) from the NanoXact product line were ordered from Nanocomposix Inc. (San Diego, CA, USA). The nominal size of both types of AgNPs was $40 \mathrm{~nm}$ and the nominal mass concentration was $20 \mathrm{mg} \mathrm{L}^{-1}$. The detailed information about PEG-AgNPs and Citrate-AgNPs are presented in Supplementary Table A. Organic low fat milk ( $0.4 \%$ fat) was purchased in a Danish supermarket from Arla Foods amba (Viby J, Denmark).

\subsection{Incubation of AgNPs in food simulants and milk}

\subsubsection{Aqueous food simulants}

EU standard aqueous food simulants including $10 \% \mathrm{v} / \mathrm{v}$ ethanol (E10\%), 20\% v/v ethanol (E20\%), 50\% v/v ethanol (E50\%) , 3\% v/v acetic acid (AA3\%), and ultrapure water as control were spiked with PEG-AgNPs at a concentration of $20 \mathrm{\mu g} \mathrm{L}^{-1}$ in $15 \mathrm{~mL}$ conical based poly propylene (PP) tubes. Spiked samples were mixed by vortexing for $30 \mathrm{~s}$. Afterwards, the closed sample tubes were incubated at $40^{\circ} \mathrm{C}$ for 4 hours or 10 days in the dark in an oven (Heraeus Instrument, Hanau, Germany). After cooling to room temperature all of the aqueous simulants were diluted 1000-times with ultrapure water to a final concentration of $20 \mathrm{ng} \mathrm{L}^{-1}$ and characterized directly by spICP-MS.

\subsubsection{Food simulant olive oil}

Extra virgin olive oil as a fatty food simulant was spiked with PEG-AgNPs $\left(20 \mathrm{gg} \mathrm{L}^{-1}\right)$ and then incubated at $40^{\circ} \mathrm{C}$ for 4 hours or 10 days as described above. Spiked olive oil samples were introduced to the ICP-MS instrument as diluted emulsion (oil in water). The emulsion was prepared according to the procedure described in (Castillo et al. 1999). A volume of $2 \mathrm{~mL}$ of oil and $2 \mathrm{~mL}$ of Triton X-100 surfactant were mixed by vortexing for 3 min using a (MS2 minishaker (IKA-Werke GmbH \& Co, Germany) for 3 min to obtain a 
homogenous oil mixture. Then, $46 \mathrm{~mL}$ of water were added and vortexing continued for $5 \mathrm{~min}$ to obtain an emulsion. The total preparation time for each sample was around $10 \mathrm{~min}$. Aliquots of $250 \mu \mathrm{L}$ of the emulsion were diluted 40 -times to a final concentration of $20 \mathrm{ng} \mathrm{L}^{-1}$ PEG-AgNPs.

\subsubsection{Low fat cow milk}

Low fat cow milk ( $0.4 \%$ fat) was spiked with PEG-AgNPs at a concentration of $20 \mu^{-1}$ and then stored in a refrigerator $\left(4^{\circ} \mathrm{C}\right)$ for 5 days to mimic realistic storage conditions of milk. Afterwards, the samples were diluted 1000-times with ultrapure water and then characterized by spICP-MS. Blank samples (ultrapure water) were spiked, stored and diluted exactly in the same way as the milk samples. All samples (aqueous food simulants, olive oil and low fat milk) were spiked and incubated in duplicate. Each of the samples was diluted and analyzed by spICP-MS.

\subsubsection{Effect of sodium chloride $(\mathrm{NaCl})$}

AgNPs (PEG-AgNPs and Citrate-AgNPs) were diluted in ultrapure water $\left(20 \mathrm{~g} \mathrm{~L} \mathrm{~L}^{-1}\right)$ containing $20 \mathrm{~g} \mathrm{~L}^{-1}(2 \%)$ sodium chloride and then incubated at $40^{\circ} \mathrm{C}$ for 4 hours. After incubation, the samples were diluted 1000 times and characterized by spICP-MS.

\subsection{Incubation of Ag ions in food simulants and milk}

In order to investigate the potential of AgNPs formation from released Ag ions, all food simulants (aqueous and olive oil) were spiked with $\mathrm{Ag}$ ions at a concentration of $20 \mu \mathrm{g} \mathrm{L}^{-1}$ and then incubated at $40^{\circ} \mathrm{C}$ for 10 days. Milk samples were also spiked with $\mathrm{Ag}$ ions at the same concentration and stored in refrigerator $\left(4^{\circ} \mathrm{C}\right)$ for 5 days. Samples were diluted and then analyzed by spICP-MS to detect potentially formed NPs. Spiked olive oil samples were introduced to the SpICP-MS as diluted emulsion (oil in water) using triton X-100 as surfactant with the same procedure described in section 2.2.2. In order to examine the possibility of the reduction of $\mathrm{Ag}$ ions to AgNPs at low Ag mass concentrations $\left(20 \mu \mathrm{g} \mathrm{L}^{-1}\right)$ and in alkaline conditions, an experiment for the production of colloidal metallic NPs as described by Gomes et al. was performed at decreasing $\mathrm{Ag}$ mass concentrations (Gomes et al. 2015a). Varying amounts of silver nitrate $\left(\mathrm{AgNO}_{3}\right)(6.4 \mu \mathrm{g}$ to $13.6 \mathrm{mg}$ ) and $2 \mathrm{~g}$ of PVP, which acted as stabilizing agent, were dissolved in $100 \mathrm{~mL}$ ultrapure water. In a separate flask, $32 \mathrm{~g}$ of methanol as reducing agent and $0.8 \mathrm{~g} \mathrm{NaOH}$ were dissolved in $100 \mathrm{~mL}$ of ultrapure water. A volume of $10 \mathrm{~mL}$ of methanol/ $\mathrm{NaOH}$ solution was then added to $10 \mathrm{~mL}$ of the $\mathrm{AgNO}_{3} / \mathrm{PVP}$ solution, and the resulting colloidal suspension stirred using a tube rotator for $40 \mathrm{~min}$ at room temperature. The $\mathrm{Ag}$ mass concentrations in the final solution were $43 \mathrm{mg} \mathrm{L}^{-1}$ (equivalent to $0.40 \mathrm{mmol} \mathrm{L}^{-1}$ as used by Gomes et al.), $10 \mathrm{mg} \mathrm{L}^{-1}, 1 \mathrm{mg} \mathrm{L}^{-1}, 200 \mu \mathrm{g} \mathrm{L}^{-1}$, and $20 \mu \mathrm{g} \mathrm{L}^{-1}$. As control/blank samples, AgNO $/ \mathrm{PVP}$ solution and methanol/ $\mathrm{NaOH}$ solution were analyzed. The colloidal suspensions were diluted to a final concentration of $20 \mathrm{ng} \mathrm{L}^{-1}$ with ultrapure water and characterized by SpICP-MS.

The $\mathrm{pH}$ of the food simulants and the alkaline reducing solutions was determined by using a $\mathrm{pH}$ meter (PHM240, MeterLab, Radiometer, Copenhagen, Denmark). The $\mathrm{pH}$ meter was calibrated with IUPAC standard buffer solutions at three points ( $\mathrm{pH}$ of 4.005, 7.000, 10.012).

\subsection{Ultrafiltration of incubated AgNPs in food simulants}

For a time-dependent PEG-AgNP dissolution experiment, one acidic and one alcoholic food simulant (AA $3 \%$, E50\%) and ultrapure water were spiked at a PEG-AgNP mass concentration of $20 \mathrm{\mu g} \mathrm{L}^{-1}$ in $50 \mathrm{~mL}$ conical based PP tubes. The tubes were incubated at $40^{\circ} \mathrm{C}$ for 10 days with no stirring. At specific time intervals (every $2 \mathrm{~h}$ for the first half day, and then every $12-24 \mathrm{~h}$ for 14 days), $500 \mu \mathrm{L}$ of the food simulant was sampled from the tube, and the released Ag ions separated from the PEG-AgNPs using centrifugal filtration. For that, the undiluted samples were transfer to centrifugal filters with a polyethersulfone (PES) membrane and with a molecular weight cut-off of $10000 \mathrm{~g} / \mathrm{mol}$ (VWR, USA). After centrifugation for $25 \mathrm{~min}$ at $11000 \times \mathrm{g}$ in a MiniSpin centrifuge (Eppendorf AG, Germany), the filtrate was collected and mixed with $4.5 \mathrm{~mL}$ of $2 \%$ $\mathrm{HNO}_{3}$ for ICP-MS analysis. Rhodium (Rh) at a concentration of $1 \mu \mathrm{g} \mathrm{L}^{-1}$ was used as internal standard. The silver dissolution in the food simulants was monitored until pseudo-equilibrium was observed (i.e. for $350 \mathrm{~h}$ ). The silver dissolution experiments were conducted in duplicate. 
The Ag mass concentration measured in the filtered food simulants was plotted as a function of incubation time in Microsoft Excel and fitted according to the pseudo-first-order reaction equation for AgNP dissolution (Liu \& Hurt 2010; Zhang et al. 2011):

$\left[A g^{+}\right\rceil_{t}=[A g N P s\rceil_{0} \times\left[1-e^{-k t}\right]$

$t_{1 / 2}=\frac{\ln 2}{k}$

where $\mathrm{t}$ is the time $(\mathrm{h}), \mathrm{k}$ is the pseudo-first-order rate constant $\left(\mathrm{h}^{-1}\right),\left[A g^{+} l_{t}\right.$ is the concentration of ionic $\mathrm{Ag}^{+}$at time $\mathrm{t}\left(\mathrm{mg} \mathrm{Kg}^{-1}\right),\lceil A g N P s\rceil_{0}$ is the initial AgNPs concentration $\left(\mathrm{mg} \mathrm{kg}^{-1}\right)$, and $t_{1 / 2}$ is half life time of AgNPs (h).

\subsection{ICP-MS and spICP-MS analysis}

An iCAP Q ICP-MS (Thermo Fisher Scientific GmbH, Bremen, Germany) was used for all ICP-MS and spICPMS experiments. Instrument tuning was performed prior to analysis by using a tuning solution according to the manufacturer's recommendation. Instrument parameters were set as follows: forward RF power, 1550 W; plasma gas flow rate, $14 \mathrm{~L} / \mathrm{min}$; carrier gas flow rate, $0.96 \mathrm{~mL} / \mathrm{min}$; makeup gas flow rate, $0.80 \mathrm{~mL} / \mathrm{min}$. A low-flow concentric nebulizer and a Peltier-cooled cyclonic spray chamber were used. The monitored isotopes were ${ }^{197} \mathrm{Au}$ and ${ }^{107} \mathrm{Ag}$. The ${ }^{103} \mathrm{Rh}$ isotope was used as internal standard for total $\mathrm{Ag}$ determination by conventional ICP-MS. The gravimetrically determined flow rates were in the range of 0.34 to $0.37 \mathrm{~mL} \mathrm{~L}^{-1}$. Measurements were performed in "STDS mode", i.e. without a collision/reaction gas and using a "high sensitivity" skimmer cone insert $(2.8 \mathrm{~mm})$. The requirements for daily performance testing regarding instrument sensitivity were the following: $>80000 \mathrm{cps}$ for ${ }^{7} \mathrm{Li},>200000 \mathrm{cps}$ for ${ }^{59} \mathrm{Co},>400000 \mathrm{cps}$ for ${ }^{115} \mathrm{In}$, $>500000 \mathrm{cps}$ for ${ }^{238} \mathrm{U}$. The dwell time was $3 \mathrm{~ms}$ for single particle mode and $300 \mathrm{~ms}$ for total $\mathrm{Ag}$ determination.

Data processing was performed according to the methodology described by Pace (Pace et al. 2012) using a spread sheet routine. The sample flow rate was accurately determined by weighing ultrapure water at room temperature as a sample over $2 \mathrm{~min}$. Quantification of particle size was based on a calibration curve constructed from a blank (ultrapure water) and five concentration levels of certified standard solutions of silver ions ranging from 0.2 to $2.0 \mu \mathrm{g} \mathrm{L}^{-1}$, which were analyzed at the beginning of each measurement sequence. The isotope ${ }^{107} \mathrm{Ag}$ was detected using $3 \mathrm{~ms}$ dwell time for a total measurement time of $180 \mathrm{~s}$. The ICP-MS signal intensity for each standard solution was acquired by averaging the signal intensity recorded during the $180 \mathrm{~s}$ measurement time.

The transport efficiency of the liquid samples through the sample introduction system was determined according to the "particle size" method (Pace et al. 2012) by measuring a reference gold nanoparticle (AuNP) suspension (NIST 8013) with a known average particle diameter (56.0 $\pm 0.5 \mathrm{~nm}$ as determined by transmission electron microscopy by NIST) diluted $10^{6}$-times with ultrapure water and ionic gold standards $\left(0,0.2,0.5\right.$ and $\left.1.0 \mu \mathrm{g} \mathrm{L}^{-1}\right)$. First, a calibration curve that related ${ }^{197} \mathrm{Au}$ signal intensity (median of the intensity distribution) to particle mass was created using the reference AuNPs (calculated particle mass 1.8 $\mathrm{fg}$ ) in ultrapure water. Secondly, a corresponding calibration curve was constructed by determining the average ${ }^{197} \mathrm{Au}$ signal intensity for ionic Au standards at $0,0.2,0.5$ and $1.0 \mu \mathrm{g} \mathrm{L}^{-1}$. The Au concentration was converted to Au mass by multiplication with sample flow rate and dwell time. The transport efficiency was determined by dividing the slope from the calibration curve made from the ionic Au standards by the slope from the calibration curve created from the AuNPs. Particle mass was converted to particle diameter by assuming spherical particles with densities of $19.3 \mathrm{~g} / \mathrm{cm}^{3}$.

For all samples, the recorded signal intensity data were plotted (in cps) versus number of "events", to create a signal distribution histogram using Microsoft Excel (Microsoft, WA, USA). An iterative algorithm was applied where particle events were distinguished as outliers from the background signal if the measured intensity was more than five times the standard deviation of the whole data set. This principle ensured that only particle events and no background or signal from metal ions were included in the dataset, but also excluded low-intensity events corresponding to the smallest NPs (Tuoriniemi \& Cornelis 2012). For conversion of particle mass into particle diameter (in the following also called particle size) 
spherical particles with a density of $10.6 \mathrm{~g} / \mathrm{cm}^{3}$ were assumed. All samples were measured in duplicates. A washing solution containing $1 \%(\mathrm{v} / \mathrm{v}) \mathrm{HNO}_{3} 68 \%, 1 \%(\mathrm{v} / \mathrm{v}) \mathrm{HCL} 34 \%$ and $0.1(\mathrm{v} / \mathrm{v})$ Triton X-100 was used between all samples (except for AuNPs and Au ions where ultrapure water was used) to avoid potential carry over of AgNPs and Ag ions. A solution of $1 \mu \mathrm{g} \mathrm{L}^{-1}$ ionic silver was run in every measuring sequence to evaluate signal stability and potential changes of the instrument sensitivity during the day.

PEG-AgNPs which were diluted freshly every day to concentration of $20 \mathrm{ng} \mathrm{L}^{-1}$ and measured by spICP-MS were considered as control samples to assure that measurements which were performed on different days were comparable. The detection limit for dissolved silver was determined as the mean plus three times the standard deviation of the signal obtained for blanks (ultrapure water, $3 \%$ acetic acid and ethanol solvents depending on the analyzed samples), which were analyzed between samples for $1 \mathrm{~min}$.

The particle concentration and size was not reported when the number of detected particles $\mathrm{N}$ was less than 400. This corresponds to a maximum allowed relative standard deviation (RSD) (of the Poisson distribution) of $5 \%\left(\mathrm{RSD} \%=\frac{\text { standard deviation }}{\text { mean }} \%=\frac{\sqrt{N}}{N} \%\right)$. The particle number detection limit corresponds to the relative error in particle counting (Error $=2 z \sqrt{\frac{1}{N}}$ ), where the $z$ value for the $95 \%$ confidence interval is 1.96 (Tuoriniemi \& Cornelis 2012), showing that the particle number detection limit depends only on number of detected particles. Further, the ratio between detected particles and number of dwells was restricted to a maximum of $10 \%$ (i.e. 6000 particles during $180 \mathrm{~s}$ measurement time with a dwell time of 3 $\mathrm{ms}$ ) to limit the probability of multiple particle events during one dwell to $4.9 \%$.

For determination of the total silver concentration of the PEG-AgNPs stock suspension, $0.1 \mathrm{~mL}$ of diluted stock suspension $\left(20 \mu \mathrm{g} \mathrm{L}^{-1}\right)$ was digested with $0.3 \mathrm{~mL}$ concentrated $\mathrm{HNO}_{3}(68 \%)$ and $0.2 \mathrm{~mL}$ concentrated $\mathrm{HCL}(34 \%)$ overnight and then diluted with $2 \% \mathrm{HNO}_{3}$ to final volume of $10 \mathrm{~mL}$. Rh was used as internal standard for total silver determination.

Results are presented as mean \pm 1 standard deviation of two replications $(\mathrm{N}=2)$. Data processing of signal intensities and plotting of the dissolution curves was performed using Microsoft Excel. Plotting of size distributions was performed using OriginPro (Origin Lab Corporation) software.

\section{Results and discussion}

\subsection{Stability of AgNPs in food simulants}

The characteristics of $20 \mathrm{\mu g} \mathrm{L}^{-1}$ PEG-AgNPs in different food simulants before and after short (4 hours) and long incubation ( 10 days) at $40^{\circ} \mathrm{C}$ are shown in Table 1 and Supplementary Table B. The concentration $20 \mu \mathrm{g}$ $\mathrm{L}^{-1}$ was chosen because it is in the range of reported migration levels in the literature which was reviewed in our previous study (Jokar et al. 2016). The incubation conditions were selected based on Regulation (EC) No 10/2011. To mimic longer storage, a test time of 10 days (represents contact times of 3 to 30 days) and a test temperature of $40^{\circ} \mathrm{C}$ (represents contact temperatures between $20^{\circ} \mathrm{C}$ and $40^{\circ} \mathrm{C}$ ) was selected. These conditions do also cover storage times at refrigerated and frozen conditions including heating up to $70^{\circ} \mathrm{C}$ for up to 2 hours, or heating up to $100{ }^{\circ} \mathrm{C}$ for up to 15 minutes. To mimic short storage, the test time was reduced to 4 hours. There is no information on the type of nanosilver used in food containers found in the EU market available. It is further not known whether the NPs migrate with their stabilizing agents or not. PEG was selected as a relevant coating because it is an EU approved additive substance in FCMs (EFSA 2006). Moreover, PEG is usually used in polymer composites to improve retention rate and control the release of active compound in FCMs. AgNPs with a nominal size of $40 \mathrm{~nm}$ were chosen $40 \mathrm{~nm}$ is in the size range of AgNPs $(20-90 \mathrm{~nm}$ ) detected by spICP-MS in migration studies (Artiaga et al. 2015; Mackevica et al. 2016). 
Table 1: Particle number / mass concentration and concentration of dissolved Ag determined by spICP-MS of PEG-AgNPs in food simulants before and after 4 hours as well as 10 days incubation at $40^{\circ} \mathrm{C}(\mathrm{N}=2)$. The nominal spiking concentration was $20 \mathrm{mg} \mathrm{L}^{-1}$. The food simulants included ultrapure water (MQ), $3 \% \mathrm{v} / \mathrm{v}$ acetic acid (AA 3\%), 10\% v/v ethanol (E10\%), 20\% v/v ethanol (E20\%), 50\% v/v ethanol (E50\%) and olive oil.

\begin{tabular}{|c|c|c|c|c|c|c|c|c|c|}
\hline \multirow[b]{2}{*}{$\begin{array}{l}\text { Food } \\
\text { simulants }\end{array}$} & \multicolumn{3}{|c|}{$\begin{array}{l}\text { Particle number concentration }{ }^{1}\left(10^{9}\right. \\
\left.\text { particles } L^{-1}\right)\end{array}$} & \multicolumn{3}{|c|}{ Particle mass concentration ${ }^{1}\left(\mu \mathrm{g} \mathrm{L}^{-1}\right)$} & \multicolumn{3}{|c|}{$\begin{array}{l}\text { Dissolved silver background } \\
\text { concentration }\left(\mu \mathrm{g} \mathrm{L}^{-1}\right)\end{array}$} \\
\hline & $\begin{array}{l}\text { Before } \\
\text { Incubation }\end{array}$ & $\begin{array}{c}\text { Short } \\
\text { Incubation } \\
(4 \text { hours at } \\
\left.40^{\circ} \mathrm{C}\right)\end{array}$ & $\begin{array}{c}\text { Long } \\
\text { Incubation } \\
(10 \text { days at } \\
\left.40^{\circ} \mathrm{C}\right)\end{array}$ & $\begin{array}{l}\text { Before } \\
\text { Incubation }\end{array}$ & $\begin{array}{c}\text { Short } \\
\text { Incubation } \\
(4 \text { hours at } \\
\left.40^{\circ} \mathrm{C}\right)\end{array}$ & $\begin{array}{c}\text { Long } \\
\text { Incubation } \\
(10 \text { days } \\
\left.\text { at } 40^{\circ} \mathrm{C}\right)\end{array}$ & $\begin{array}{l}\text { Before } \\
\text { Incubation }\end{array}$ & $\begin{array}{c}\text { Short } \\
\text { Incubation } \\
(4 \text { hours } \\
\left.\text { at } 40^{\circ} \mathrm{C}\right)\end{array}$ & $\begin{array}{c}\text { Long } \\
\text { Incubation } \\
(10 \text { days } \\
\left.\text { at } 40^{\circ} \mathrm{C}\right)\end{array}$ \\
\hline $\begin{array}{l}\text { Ultrapure } \\
\text { water }\end{array}$ & $61.0 \pm 2.3$ & $57.2 \pm 4.3$ & $\mathrm{~N} / \mathrm{A}$ & $11.1 \pm 0.7$ & $11.1 \pm 0.4$ & $\mathrm{~N} / \mathrm{A}$ & $<L O D$ & $<L O D$ & $11.9 \pm 4.1$ \\
\hline AA $3 \%$ & $66.8 \pm 1.9$ & $42.5 \pm 0.8$ & $\mathrm{~N} / \mathrm{A}$ & $12.9 \pm 0.6$ & $7.5 \pm 0.10$ & $\mathrm{~N} / \mathrm{A}$ & $<$ LOD & $<L O D$ & $12.9 \pm 0.1$ \\
\hline E10\% & $80.2 \pm 1.3$ & $67.2 \pm 2.5$ & $\mathrm{~N} / \mathrm{A}$ & $16.2 \pm 0.1$ & $12.0 \pm 0.7$ & $\mathrm{~N} / \mathrm{A}$ & $<$ LOD & $<L O D$ & $6.1 \pm 0.5$ \\
\hline E20\% & $52.4 \pm 2.1$ & $53.7 \pm 1.7$ & $\mathrm{~N} / \mathrm{A}$ & $9.6 \pm 0.4$ & $9.9 \pm 0.1$ & $\mathrm{~N} / \mathrm{A}$ & $<L O D$ & $<L O D$ & $<L O D$ \\
\hline E50\% & $59.2 \pm 4.3$ & $64.3 \pm 0.1$ & $51.1 \pm 6.5$ & $11.2 \pm 0.1$ & $12.4 \pm 0.0$ & $8.6 \pm 0.3$ & $<L O D$ & $<L O D$ & $<$ LOD \\
\hline Olive Oil & $72.6^{2}$ & $30.4 \pm 1.2$ & $7.9 \pm 1.1$ & $14.2^{2}$ & $6.4 \pm 0.2$ & $1.1 \pm 0.2$ & $<L O D$ & $<L O D$ & $<L O D$ \\
\hline
\end{tabular}

The limit of detection (LOD) for dissolved background was in the range of 4.65 to $9.16 \mu \mathrm{L}-1$ (N= 7) considering a dilution factor of 1000 .

$\mathrm{N} / \mathrm{A}$ : The particle number and mass concentration are not shown when less than 400 particles were detected, which correspond to $\geq 5 \%$ relative standard deviation of the Poisson distribution.

${ }^{1}$ results are presented as mean \pm standard deviation $(\mathrm{N}=2)$

${ }^{2}$ There was no replication

Before incubation, the initial particle mass concentrations of AgNPs in food simulants that were measured by spICP-MS on 7 different experimental days ranged from 9.6 to $16.2 \mathrm{\mu g} \mathrm{L}^{-1}$ (corresponding to initial particle number concentration of $52 \times 10^{9}$ to $80 \times 10^{9}$ particles $\mathrm{L}^{-1}$ ). This corresponds to mass recoveries in the range of 46 to $77 \%$ when compared to the concentrations specified by the supplier. Based on our own ICP$\mathrm{MS}$ analysis, the Ag mass concentration of the PEG-AgNPs stock suspension was $16.3 \pm 0.2 \mathrm{mg} \mathrm{L}^{-1}(\mathrm{~N}=3)$. In relation to this concentration, Ag mass recoveries by spICP-MS were in the range of 60 to $100 \%$. It has been demonstrated in an international interlaboratory study for sizing and quantification of AgNPs in food simulants by spICP-MS that the average repeatability and reproducibility standard deviations for Ag particle number concentration were only $11 \%$ and $78 \%$, respectively (Linsinger et al. 2014). In addition, no differences between samples prepared in water or $10 \%$ ethanol were detected in the study by Linsinger et al. (in contrast to our study, Table 1). It is therefore likely that the observed variation of initial Ag particle number and mass concentrations was caused by the spICP-MS method and not by the different food simulants. In addition, the lower initial size of AgNPs of 31-32 nm (Supplementary Table B) in comparison to the nominal size $(41 \pm 4 \mathrm{~nm})$ of the supplier could be explained by the different methods of size measurement. The size reported by the supplier is based on the TEM measurement of 100 particles, while the size measured by spICP-MS is based on the median mass-equivalent diameter of 400 to 1000 particles. The size distribution measured by spICP-MS may also be slightly skewed to lower sizes because of incomplete particle events. After incubation for 4 hours at $40^{\circ} \mathrm{C}$, no statistically significant changes $(p<$ 0.05 ) of particle number and mass concentration as well as median particle size were observed in ultrapure water, E20\% and E50\% (Table 1 and Figure 1). A reduction of the particle number concentration of 16\%, $36 \%$ and $58 \%$ was observed for E10\%, AA3\% and olive oil, respectively. The comparison of the size distribution of PEG-AgNPs after short incubation relative to before incubation (Figure 1) revealed a slight shift to lower size for AA3\%, most likely due to some dissolution. Additionally, particle agglomeration was observed in olive oil (size range above $50 \mathrm{~nm}$, Figure 1), which could explain the higher reduction of particle number concentration in olive oil (58\%) than in AA3\% (36\%). The dissolved silver background concentrations were below LOD in all samples before and after short incubation. It needs to be highlighted 
that the LOD was with $6 \mu \mathrm{g} \mathrm{L}^{-1}$ relatively high, because the dilution factors for spICP-MS analysis were not optimized towards particle or ion detection for each individual sample. Instead all samples were diluted by the same factor (1000-times) to see relative changes directly when comparing samples before and after incubation.
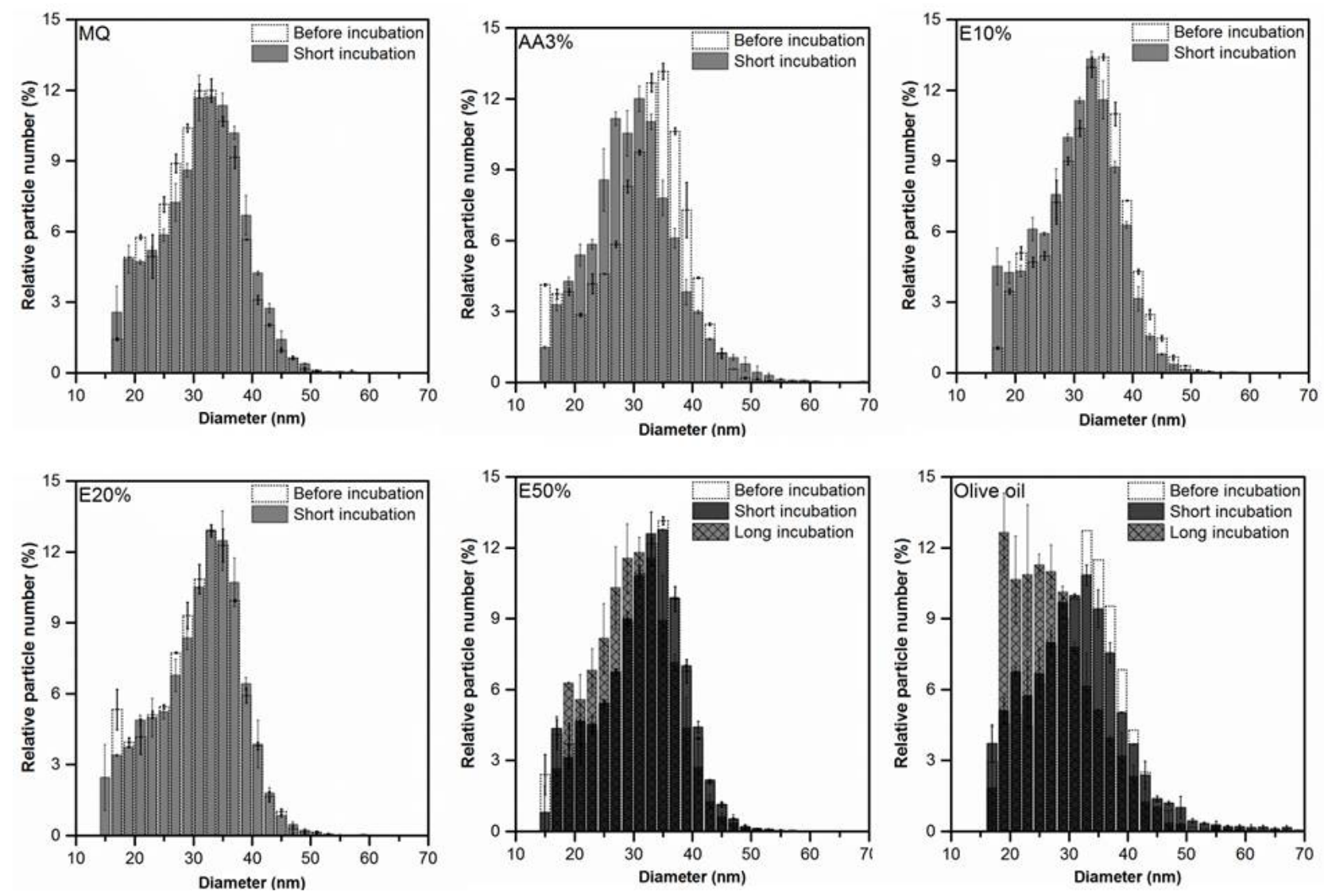

Figure 1. Size distributions determined by spICP-MS of PEG-AgNPs in ultrapure water (MQ) and food simulants before and after 4 hour (short) as well as 10 day (long) incubation at $40^{\circ} \mathrm{C}$. The food simulants included $3 \% \mathrm{v} / \mathrm{v}$ acetic acid (AA 3\%), 10\% v/v ethanol (E10\%), 20\% v/v ethanol (E20\%), 50\% v/v ethanol (E50\%) and olive oil. The size distributions of PEG-AgNPs after 10 day incubation in ultrapure water, AA3\%, $\mathrm{E} 10 \%$, and $\mathrm{E} 20 \%$ were not displayed because the number of detected particles was too low $(<400)$.

After incubation for 10 days at $40^{\circ} \mathrm{C}$, more than $95 \%$ of the particle mass disappeared in $\mathrm{AA} 3 \%, \mathrm{E} 10 \%$, $\mathrm{E} 20 \%$, and ultrapure water while the reduction in particle mass concentration was $92.2 \%$, and $23.2 \%$ for olive oil and E50\%. The size distributions of PEG-AgNPs after long incubation are only shown for ultrapure water, olive oil and E50\% (Figure 1 ) in which a sufficient number of particles $(>400)$ could be detected. The size distribution of AgNPs did not change significantly for E50\%, while a shift to smaller median sizes from $31 \mathrm{~nm}$ to $26 \mathrm{~nm}$ was observed in ultrapure water and olive oil (Supplementary Table B). A slight indication of agglomeration was also revealed in the size distribution of olive oil (Figure 1). Elevated dissolved silver background was clearly observed for all simulants after long term incubation, which can be attributed of dissolved silver ions and/or small AgNPs (< size LOD). It means that the PEG-AgNPs were dissolving during the incubation period leading to a decrease in particle size and eventually formation of $\mathrm{Ag}$ ions. The higher minimum detectable size after 10 days $(18.5 \mathrm{~nm})$ compared to 4 hours incubation $(16.3 \mathrm{~nm})$ could be attributed to the increased signals of dissolved silver in simulants (Tuoriniemi et al. 2015; Montaño et al. 2016).

The largest increase of the dissolved silver background was observed in ultrapure water and AA3\%. The dissolved silver background is caused by silver ions and particles smaller than the size LOD. Dissolution of AgNPs in AA3\% was also described by others (Echegoyen \& Nerín 2013; Hannon, Kerry, et al. 2015; Ntim et al. 2015; Mackevica et al. 2016). Dissolution has been reported to be a heterogeneous oxidation reaction involving dissolved oxygen and protons (Liu \& Hurt 2010). The $\mathrm{pH}$ of AA3\% was 2.5 which was much lower than the $\mathrm{pH}$ values of the other simulants. The low $\mathrm{pH}$ greatly increases the dissolution process because of 
increased proton concentration. The $\mathrm{pH}$ values of the food simulants were 6.9, 4.4, 5.8, 6.3 for ultrapure water, E10\%, E20\%, and E50\% respectively. The literature demonstrated the $\mathrm{pH}$ dependency of agglomeration and dissolution of AgNPs in different matrices. For example, Axson et al. (Axson et al. 2015) observed a growth in AgNPs size of $20 \mathrm{~nm}$ while the pH increased from 2 to 6 in simulated gastric fluid by nanoparticle tracking analysis. Ntim et al. (Ntim et al. 2016) also revealed by spICP-MS that the size distribution of $60 \mathrm{~nm}$ PVP-coated AgNPs after incubation for 4 hours at $100{ }^{\circ} \mathrm{C}$ shifted to lower size in AA3\% and that only $8 \%$ of the AgNP mass could be recovered, while the number concentration did not change significantly (size LOD $=10 \mathrm{~nm}$ ).

E50\% preserved the PEG-AgNPs the most with limited dissolution and no recognizable change of the size distribution. In a similar way, (Ntim et al. 2016) observed preservation of PVP-coated AgNPs in 50\% ethanol when incubated for 4 hours at $100^{\circ} \mathrm{C}$.

The effects of the presence of $\mathrm{NaCl}$ salt on the stability and transformation of AgNPs was investigated by incubating PEG-AgNPs at $40^{\circ} \mathrm{C}$ for 4 hours in $20 \mathrm{~g} \mathrm{~L}^{-1}(2 \%) \mathrm{NaCl}$ solution. This $\mathrm{NaCl}$ concentration is considered a high sodium level in foods (USFDA 2016). The number of detected particles decreased immediately by $12 \%$ by adding $\mathrm{NaCl}$ (in comparison to ultrapure water). After 4 hours incubation, the number of detected particles was $47 \%$ less in samples containing $\mathrm{NaCl}$ than in samples without $\mathrm{NaCl}$ and the particle size distribution was shifted towards lower sizes. The dissolved silver background was significantly higher (about twice as high) in the presence of $\mathrm{NaCl}$, leading to an increase of the minimum detectable particle size. The results point towards enhanced dissolution of PEG-AgNPs in the presence of $\mathrm{NaCl}$. The dissolution behavior of AgNPs in the presence of $\mathrm{Cl}^{-}$ions was shown to dependent on the $\mathrm{Cl} / \mathrm{Ag}$ ratio (Levard et al. 2012; Levard et al. 2013). In the presence of small amounts of $\mathrm{Cl}^{\text {; }}$, insoluble $\mathrm{AgCl}$ precipitates, while at higher levels of $\mathrm{Cl}^{-}$soluble anionic $\mathrm{Ag}$ complexes such as $\mathrm{AgCl}_{2}^{-}, \mathrm{AgCl}_{3}{ }^{2-}$ and $\mathrm{AgCl}_{4}{ }^{3-}$ may form. Dissolution of AgNPs can also be inhibited in the presence of $\mathrm{Cl}^{-}$due to the precipitation of insoluble $\mathrm{AgCl}$ on the surface of the AgNPs. Due to these complex processes, the dissolution rate of AgNPs in aerobic systems and in the presence of $\mathrm{Cl}^{-}$is difficult to predict (Levard et al. 2012). Levard et al. showed that for $\mathrm{Cl} / \mathrm{Ag} \leq 2675$, the rate of dissolution of PVP-stabilized AgNPs in the presence of $\mathrm{Cl}^{-}$was slower compared to AgNPs in deionized water, but for a high $\mathrm{Cl} / \mathrm{Ag}$ ratio $(\mathrm{Cl} / \mathrm{Ag}=26750)$, the rate of $\mathrm{AgNP}$ dissolution was greater than the deionized water control (Levard et al. 2013). In the presented study, a large excess of $\mathrm{Cl}$ in comparison to $\mathrm{Ag}$ was present (Cl/Ag ratio of approximately 1800000), which was in agreement with the observed increased dissolution.

To investigate whether the PEG-coating had an influence on the behavior of AgNPs in the presence of $\mathrm{NaCl}$, e.g. reduced or delayed dissolution, the experiment was repeated with citrate stabilized AgNPs. The results indicated that PEG-AgNPs and Citrate-AgNPs behaved similar in terms of increase in dissolved silver background, decrease in the number of detected particles and shift to smaller particles sizes after 4 hour incubation at $40^{\circ} \mathrm{C}$ and in the presence of salt.

The different dissolution behavior of AgNPs in the presence of $\mathrm{NaCl}$ in comparison to the absence of $\mathrm{NaCl}$ demonstrated that food simulants might not always be suitable for mimicking real foods in migration studies of NPs. AgNPs may be preserved in food simulants, while the presence of $\mathrm{NaCl}$ in real food could cause dissolution of migrating AgNPs. Studies investigating the fate of (migrating) NPs in real foods are required.

\subsection{Stability of Ag ions in food simulants}

It has been postulated that the finding of AgNPs in migration solutions from FCMs could be explained with the migration of silver ions followed by reduction and formation of NPs (Noonan et al. 2014; Mackevica et al. 2016). To investigate this hypothesis, we spiked silver ions to selected food simulants and incubated the samples for 10 days at $40^{\circ} \mathrm{C}$ and at a concentration relevant for migration studies. However, no AgNPs (size LOD, $19 \pm 1 \mathrm{~nm}$ ) were detected in any of the food simulants (Supplementary Figure1).

Two potential reasons for our findings could be i) the chemical composition of food simulants, which does not provide appropriate reducing agents for the reduction of silver ions to AgNPs, or ii) the low concentration of silver ions, which is relevant for migration conditions but much lower than the concentrations used for NP synthesis by reduction of ions as described in the literature (Lee et al. 2013; 
Gomes et al. 2015b). To address this, we provided the ideal alkaline reduction conditions and reduced the silver concentration stepwise down to $20 \mathrm{mg} \mathrm{L}^{-1}$ of silver nitrate. The $\mathrm{pH}$ of the alkaline medium containing silver nitrate, reducing agent (methanol- $\mathrm{NaOH}$ ) and stabilizing agent (PVP) was 13.2, which was significantly higher than the $\mathrm{pH}$ of all food simulants. The results demonstrated the formation of NPs at silver mass concentrations of $40 \mathrm{mg} \mathrm{L}^{-1}, 10 \mathrm{mg} \mathrm{L}^{-1}, 1 \mathrm{mg} \mathrm{L}^{-1}$ and $200 \mathrm{~g} \mathrm{~L}^{-1}$, while no particles were detected at $20 \mu \mathrm{g} \mathrm{L}^{-1}$ (Supplementary Figure 2). We conclude that at an initial Ag concentration of $20 \mu \mathrm{g} \mathrm{L}^{-1}$ and below, it is unlikely that AgNPs larger than $20 \mathrm{~nm}$ are formed.

A

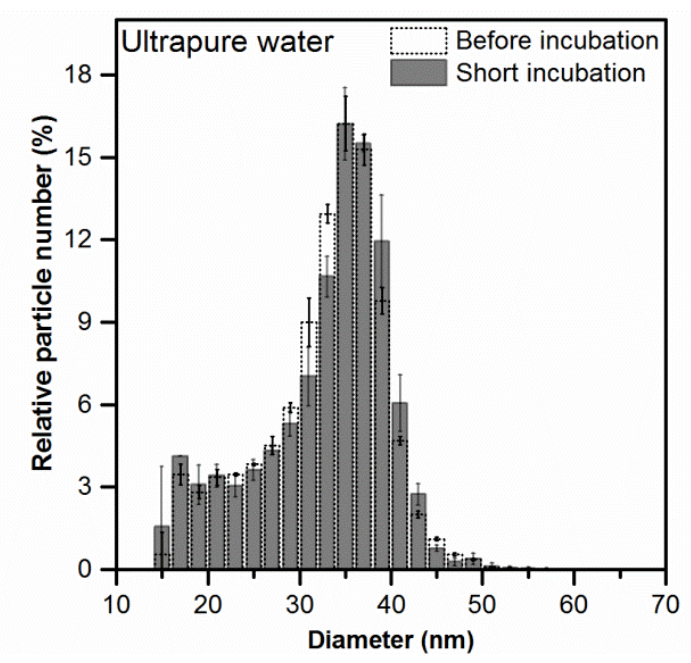

B

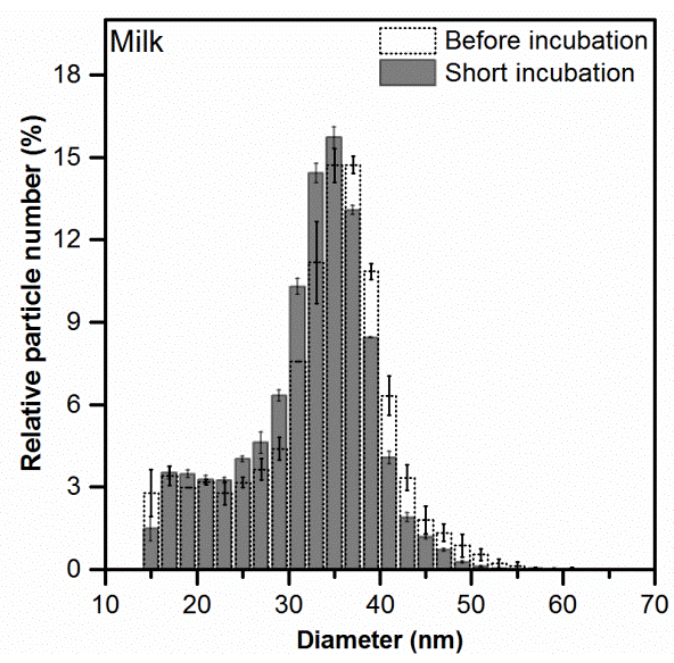

Figure 2. Size distributions determined by spICP-MS of PEG-AgNPs in ultrapure water (A) and in milk (B) before and after storage for 5 days at $4^{\circ} \mathrm{C}$.

\subsection{Stability of AgNPs and Ag ions in low fat cow milk}

In order to investigate if AgNPs behave in real food matrix similar as in a food simulant, we spiked pasteurized low fat cow milk ( $\mathrm{pH}=6.7)$ with PEG-AgNPs and compared its behavior to corresponding food simulant (E50\%). Low fat milk was selected because it is complex food matrix and no matrix degradation or NP extraction method is required as in the case of solid foods before spICP-MS analysis. Additionally, migration of Ag ions or AgNPs from nano-based drinking bottles or similar, that are available on the market, into milk is possible.

The samples were stored in a refrigerator at $4^{\circ} \mathrm{C}$ for 5 days which are relevant conditions for the storage of milk. The spICP-MS results are shown in Table 2. The particle number concentration decreased by more than $50 \%$ in ultrapure water (studied as control) after 5 days of storage at $4^{\circ} \mathrm{C}$, while the number of particles did not change significantly in milk. In both, milk and ultrapure water, the dissolved silver background was below LOD. The size distribution of PEG-AgNPs (Figure 2) did not change by refrigeration. The median particle size did not change significantly for ultrapure water $(33.9 \mathrm{~nm}$ before and $34.5 \mathrm{~nm}$ after storage) and milk ( $34.7 \mathrm{~nm}$ before and $33.4 \mathrm{~nm}$ after storage).

Table 2: Particle number / mass concentration and concentration of dissolved Ag determined by spICP-MS of PEG-AgNPs in ultrapure water and low fat cow milk before and after 5 hours incubation at $4^{\circ} \mathrm{C}(\mathrm{N}=2)$. The nominal spiking concentration was $20 \mu \mathrm{g} \mathrm{L}^{-1}$.

\begin{tabular}{|c|c|c|c|c|c|c|}
\hline \multirow{2}{*}{ Medium } & \multicolumn{2}{|c|}{$\begin{array}{c}\text { Particle number concentration } \\
\left.\text { (particles } \mathrm{L}^{-1}\right) \times 10^{9}\end{array}$} & \multicolumn{2}{c|}{ Particle mass concentration ${ }^{1}\left(\mu \mathrm{L}^{-1}\right)$} & \multicolumn{2}{|c|}{$\begin{array}{c}\text { Dissolved silver background } \\
\text { concentration }\left(\mu \mathrm{L}^{-1}\right)\end{array}$} \\
\cline { 2 - 6 } & $\begin{array}{c}\text { Before } \\
\text { Refrigeration }\end{array}$ & $\begin{array}{c}\text { After } \\
\text { Refrigeration for } \\
5 \text { days }\end{array}$ & $\begin{array}{c}\text { Before } \\
\text { Refrigeration }\end{array}$ & $\begin{array}{c}\text { After } \\
\text { Refrigeration for } \\
5 \text { days }\end{array}$ & $\begin{array}{c}\text { Before } \\
\text { Refrigeration }\end{array}$ & $\begin{array}{c}\text { After } \\
\text { Refrigeration for } \\
5 \text { days }\end{array}$ \\
\hline $\begin{array}{c}\text { Ultrapure } \\
\text { water }\end{array}$ & $69.1 \pm 7.7$ & $21.90 \pm 5.4$ & $14.7 \pm 1.8$ & $4.7 \pm 1.1$ & $<$ LOD & $<$ LOD \\
\hline
\end{tabular}




\begin{tabular}{|c|c|c|c|c|c|c|}
\hline Milk & $89.8 \pm 4.8$ & $96.8 \pm 0.5$ & $20.9 \pm 0.2$ & $19.9 \pm 0.1$ & $<$ LOD & $<$ LOD \\
\hline
\end{tabular}

The limit of detection (LOD) for dissolved background was $10.75 \pm 2.18 \mu \mathrm{g} \mathrm{L}^{-1}$

In summary, low fat cow milk preserved PEG-AgNPs more than ultrapure water, which is in agreement with the incubation of AgNPs in food simulants (Table 1) and in which E50\% is the simulant representative for dairy products. As in the case of ethanol, the organic matter in milk appears to enhance the stability of the AgNPs. The stabilizing effect of dissolved organic matter has, for example, been demonstrated for PVPcoated AgNPs in environmentally relevant aqueous samples, where reduced dissolution and aggregation was observed after addition of humic acid (Yu et al. 2014).

Milk samples were also spiked with silver ions to investigate the potential of AgNPs formation. The results showed no evidence of NPs (Supplementary Figure 1). The green synthesis of AgNPs using cow milk as reducing agent at room temperature was demonstrated (Lee et al. 2013). However, the concentration of silver nitrate for the synthesis was $1 \mathrm{mM}$ of equal to $100 \mathrm{mg} \mathrm{L}^{-1}$ which is 5000 -times more than in our experiment.

\subsection{Dissolution kinetics of AgNPs in food simulants}

It is recognized that dissolution of NPs is a complex and dynamic process and is governed by complex kinetics. It is critical to determine rate constants and subsequent lifetimes of NPs in food/food simulants because stability and durability of NPs is an important aspect of risk assessment (Utembe et al. 2015)

The dissolution rate of PEG-AgNPs into Ag ions and the subsequently half life time of PEG-AgNPs were determined in ultrapure water and the two food simulants, AA3\% and E50\% (Figure 3 and Table 3). The food simulants were selected because the most dissolution and preservation of AgNPs were observed in AA3\% and E50\%, respectively (Table1). As shown in Table 3, coefficients of determination of 0.73-0.92 were obtained for the three food simulants based on fitting to a pseudo-first-order reaction (Equation 1). Thus, a variation of $89 \%-92 \%$ of AgNPs dissolution into ions in MQ water and AA3\% fitted to Equation $1 . \mathrm{R}^{2}$ should be $\geq 0.80$ for a good fitness of a model (Joglekar \& A.T May 1987). The low $R^{2}$ for $E 50 \%(72 \%)$ could be attributed to the dissolved $\mathrm{Ag}$ concentration being close to the LOD (Figure 3). An increase of the concentration of silver ions was observed in all three matrices but at quiet different rates. After $24 \mathrm{~h}$, more than $50 \%$ of the initial concentration of AgNPs changed to ionic form in AA $3 \%$, while it was less than $10 \%$ and $5 \%$ for ultrapure water and $\mathrm{E} 50 \%$, respectively.

Table 3. Dissolution rate constant $k$, half-life $t_{1 / 2}$ and coefficient of determination $R^{2}$ based on a Pseudofirst-order kinetic equation for fitting the dissolution kinetics of PEG-AgNPs in different food simulants.

\begin{tabular}{|c|c|c|c|}
\hline Food simulants & $\mathrm{k}\left(\mathrm{h}^{-1}\right)$ & $\mathrm{t}_{1 / 2}$ (day) & $\mathrm{R}^{2}$ \\
\hline Ultrapure water & 0.00234 & $\begin{array}{c}12.340 \\
(269.2 \mathrm{~h})\end{array}$ & 0.9213 \\
\hline AA3\% & 0.02789 & 1.035 & 0.8207 \\
& & $(24.8 \mathrm{~h})$ & \\
\hline E50\% & 0.00033 & 88.444 & 0.7318 \\
& & $(2122.6 \mathrm{~h})$ & \\
\hline
\end{tabular}




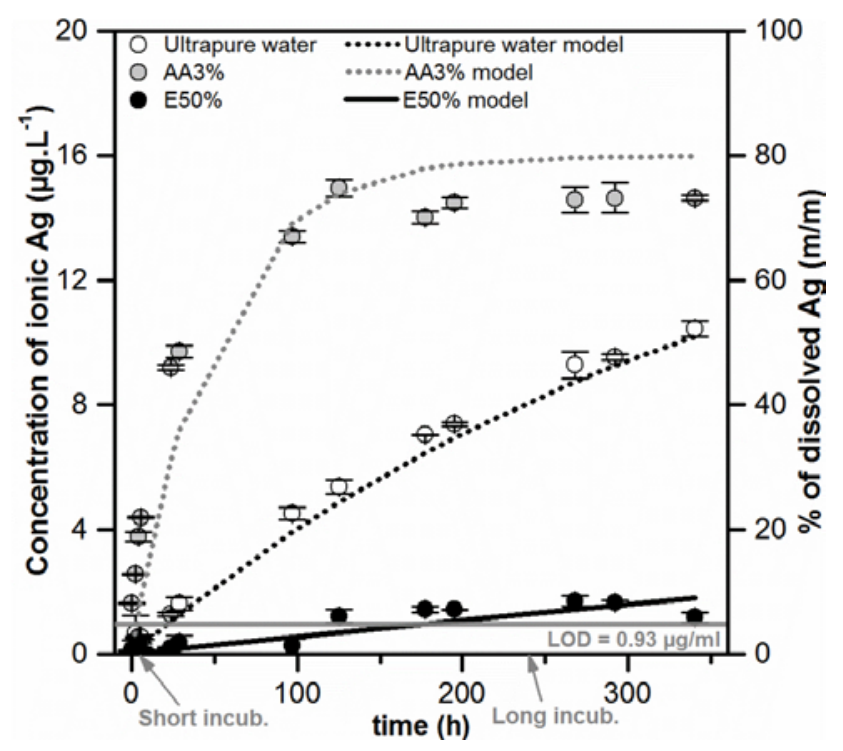

Figure 3. Dissolution curves for PEG-AgNPs incubated in ultrapure water and food simulants (AA3\% $=3 \%$ acetic acid and $\mathrm{E} 50 \%=50 \%$ ethanol) for 14 days at $40^{\circ} \mathrm{C}$ based on filtration experiments followed by ICP-MS analysis of the filtrates. The continuous lines are the results from fitting using an exponential fit function.

The percentages of dissolved Ag (compared to the total Ag concentration) determined by spICP-MS after 10 days incubation time were higher than by ultrafiltration followed by ICP-MS analysis (spICP-MS: $100 \%$, $100 \%$, and < LOD for ultrapure water, AA3\%, and $\mathrm{E} 50 \%$, respectively; ultrafiltration: $40 \%, 85 \%$, and $5 \%$ for ultrapure water, $\mathrm{AA} 3 \%$, and $\mathrm{E} 50 \%$, respectively). This corresponded to a difference of $46.7 \%$ and $18.5 \%$, for ultrapure water and AA3\%, respectively. The reason for the higher values determined by SpICP-MS can be related to the "size cut-off" of the two methods. spICP-MS considers ions but also NPs below size LOD (in our case NPs smaller $20 \mathrm{~nm}$ ) as "dissolved" Ag. Ultrafiltration used a filter with a molecular cut-off of $10000 \mathrm{~g} / \mathrm{mol}$. This corresponds to NPs of a few nanometers in size.

The results from the fitting are listed in Table 3. The Pseudo-first-order kinetic equation was fitted well to ultrapure water and $A A 3 \%$, while it was not fitted fairly to $E 50 \%$. This could be attributed to the low level of measured silver in E50\% which was close to the LOD $\left(1.34 \mu \mathrm{g} \mathrm{L}^{-1}\right)$. The dissolution rate constant $\mathrm{k}$ ranged from 0.0003 for E50\% to $0.027 \mathrm{~h}^{-1}$ for AA3\%. The half-life time $t_{1 / 2}$ of PEG-AgNPs in E50\% was 88 -times larger than for AA3\%. In the literature, half-life times of AgNPs have been presented in a wide range from $5.4 \mathrm{~s}$ to $723 \mathrm{~h}$ depending on particle size, initial NP concentration and ionic strength of solvent (Utembe et al. 2015).

In another study, the dissolution rate constant of $60 \mathrm{~nm}$ PVP-coated AgNPs was stated $0.027 \mathrm{~min}^{-1}$ at $100^{\circ} \mathrm{C}$ incubation in $3 \%$ acetic acid which was reduced to $0.015 \mathrm{~min}^{-1}$ by adding $\mathrm{NaCl}$ because of bonding of released $\mathrm{Ag}$ ions to chloride and precipitation as $\mathrm{AgCl}$, which was removed via the ultrafiltration process and consequently leading to a decrease of silver ions detected by ICP-MS (Ntim et al. 2016). The higher dissolution constant rate of AgNPs in AA3\% (1.621 h $\left.{ }^{-1}\right)$ compared to our experiment $\left(0.027 \mathrm{~h}^{-1}\right)$ could be related to the lower initial AgNPs concentration $\left(2.5 \mu \mathrm{g} \mathrm{L}^{-1}\right.$ versus $\left.20 \mu \mathrm{g} \mathrm{L}^{-1}\right)$ and also the higher incubation temperature $\left(100^{\circ} \mathrm{C}\right.$ versus $\left.40^{\circ} \mathrm{C}\right)$.

\section{Summary and conclusions}

This study highlighted the challenges of studying the potential migration of AgNPs from nano-enabled FCMs. The results supported previous studies that AgNPs, dislike molecules, behaved differently in different food simulants and migration conditions. The results demonstrated changes in AgNPs characteristics in terms of size, particle concentration, and dissolved ionic concentration during long term migration (10 days at $40^{\circ} \mathrm{C}$ ). The results demonstrated the potential transformation of AgNPs during migration testing mainly by dissolution. The dissolution behavior of AgNPs is highly influenced by the composition of food simulants and also migration conditions including time and temperature. AgNPs behaved in real food (low fat milk) in 
the same way as in the corresponding food simulant (Ethanol 50\%), however it might not applied for other foods as we showed that the presence of salt $(\mathrm{NaCl})$ enhanced dissolution under migration conditions.

Further, we conclude that it is not likely that AgNPs evidence in migration studies is a result of migration of $\mathrm{Ag}$ ions followed by reduction. Additionally, we do not expect the formation of AgNPs from migrating ions in real food because of the typically low concentrations of $\mathrm{Ag}$ ions that can migrate ( $\mu \mathrm{g} \mathrm{L}^{-1}$ range), as we could not detect AgNPs at these concentrations even under conditions that support particle formation (alkaline, presence of reducing agents).

The worst-case conditions in terms of temperature and time that are applied in migration testing need to be revised for evaluating the migration of NPs. The worst-case conditions may lead to a maximum diffusion of small molecules from FCMs at corresponding food storage conditions, but not necessarily to the maximum migration of NPs. NPs might dissolve or aggregate under migration test conditions but not under realistic conditions, which may lead to an underestimation of NP migration in real exposure scenarios.

SpICP-MS was used for detection and characterization of AgNPs in aqueous and fatty food simulants and low-fat cat milk. The advantages of spICP-MS for studying the behavior of NPs under migration conditions were minimal required sample preparation (and consequently a reduced risk of artefacts) and high sensitivity, which allowed studies at relevant NP concentrations, i.e. in the $\mathrm{ng} \mathrm{L}^{-1}$ range. Further, spICP-MS allowed the determination of particle size distribution, mass and number concentration as well as dissolved fraction during one analysis. For obtaining optimum data for NPs and dissolved background, it can be necessary to analyze the same sample at different dilution factors as suggested by Schwertfeger et al. (Schwertfeger et al. 2016). The drawbacks of spICP-MS are i) low reproducibility of particle mass and number concentrations between days, ii) the inability to detect very small NPs $(<10 \mathrm{~nm})$, iii) the inability to recognize NPs chemical composition (for example silver chloride or silver sulfate in case of AgNPs) and shape, and iv) the inability to distinguish between single NPs and their aggregates/agglomerates.

For the risk assessment of nano-based FCMs, exposure to both the ionic and the particulate form of the analyte of interest has to be considered. Further research should focus on the influence of further food components on the physicochemical characteristics of NPs released form nano-based FCMs.

\section{Acknowledgements}

This work was supported by the Marie Curie Actions of the European Union's Seventh Framework Programme (FP7/2007-2013) under REA grant agreement number 609405 (COFUNDPostdocDTU) and by The Fund of Consul George Jorck and his wife, Emma Jorck. Further, we would like to thank the Danish Veterinary and Food Administration for financial support. Annette Landin and Birgitte Koch Herbst from Research Group of Nano-Bio Science, National Food Institute, Technical University of Denmark are thanked for laboratory help.

\section{References}

Artiaga G, Ramos K, Ramos L, Cámara C, Gómez-Gómez M. 2015. Migration and characterisation of nanosilver from food containers by AF4-ICP-MS. Food Chem [Internet]. 166:76-85. Available from: http://dx.doi.org/10.1016/j.foodchem.2014.05.139

Axson JL, Stark DI, Bondy AL, Capracotta SS, Maynard AD, Philbert MA, Bergin IL, Ault AP. 2015. Rapid Kinetics of Size and pH-Dependent Dissolution and Aggregation of Silver Nanoparticles in Simulated Gastric Fluid. J Phys Chem C. 119:20632-20641.

Castillo JR, Jiménez MS, Ebdon L. 1999. Semiquantitative simultaneous determination of metals in olive oil using direct emulsion nebulization. J Anal At Spectrom. 14:1515-1518.

Echegoyen Y, Nerín C. 2013. Nanoparticle release from nano-silver antimicrobial food containers. Food Chem Toxicol [Internet]. [cited 2013 Nov 15]; 62:16-22. Available from: http://www.sciencedirect.com/science/article/pii/S0278691513005565

EFSA. 2009. Scientific Opinion of the Scientific Committee on a request from the European Commission on the Potential Risks Arising from Nanoscience and Nanotechnologies on Food and Feed Safety. EFSA J. 958:1-39.

von Goetz N, Fabricius L, Glaus R, Weitbrecht V, Günther D, Hungerbühler K. 2013. Migration of silver from 
commercial plastic food containers and implications for consumer exposure assessment. Food Addit Contam Part A [Internet]. [cited 2013 Nov 16]; 30:612-20. Available from: http://www.ncbi.nlm.nih.gov/pubmed/23406534

Gomes JF, Garcia AC, Ferreira EB, Pires C, Oliveira VL, Tremiliosi-filho G, Gasparotto LHS. 2015a. New insights into the formation mechanism of $\mathrm{Ag}, \mathrm{Au}$ and $\mathrm{AgAu}$ nanoparticles in aqueous alkaline media : alkoxides from alcohols, aldehydes and ketones as universal reducing agents + . Phys Chem Chem Phys [Internet]. 17:21683-21693. Available from: http://dx.doi.org/10.1039/C5CP02155C

Gomes JF, Garcia AC, Ferreira EB, Pires C, Oliveira VL, Tremiliosi-filho G, Gasparotto LHS. 2015b. New insights into the formation mechanism of $\mathrm{Ag}, \mathrm{Au}$ and $\mathrm{AgAu}$ nanoparticles in aqueous alkaline media : alkoxides from alcohols, aldehydes and ketones as universal reducing agents †. Phys Chem Chem Phys. 17:21683-21693.

Hannon JC, Cummins E, Kerry J, Cruz-Romero M, Morris M. 2015. Advances and challenges for the use of engineered nanoparticles in food contact materials. Trends Food Sci Technol [Internet]. 43:43-62. Available from:

http://linkinghub.elsevier.com/retrieve/pii/S092422441500028X

Hannon JC, Kerry JP, Cruz-Romero M, Azlin-Hasim S, Morris M, Cummins E. 2015. Assessment of the migration potential of nanosilver from nanoparticle coated low density polyethylene food packaging into food simulants. Food Addit Contam Part A [Internet]. 33:167-178. Available from:

http://www.tandfonline.com/doi/full/10.1080/19440049.2015.1114184

Hassellöv M, Readman JW, Ranville JF, Tiede K. 2008. Nanoparticle analysis and characterization methodologies in environmental risk assessment of engineered nanoparticles. Ecotoxicology [Internet]. [cited 2013 Nov 12]; 17:344-61. Available from: http://www.ncbi.nlm.nih.gov/pubmed/18483764

Joglekar A., A.T May. 1987. Product excellence through design of experiments. In: Food Prod Dev From Concept to Marketpl. [place unknown]; p. 875-867.

Jokar M, Pedersen GA, Loeschner K. 2016. Six open questions about the migration of engineered nano-objects from polymer-based food-contact materials: a review. Food Addit Contam Part A [Internet]. 0:1-17. Available from: https://www.tandfonline.com/doi/full/10.1080/19440049.2016.1271462

Lee K-J, Park S-H, Govarthanan M, Hwang P-H, Seo Y-S, Cho M, Lee W-H, Lee J-Y, Kamala-Kannan S, Oh B-T. 2013. Synthesis of silver nanoparticles using cow milk and their antifungal activity against phytopathogens. Mater Lett [Internet]. 105:128-131. Available from: http://www.sciencedirect.com/science/article/pii/S0167577X13005508

Levard C, Hotze EM, Lowry G V., Brown GE, Hotze ME, Lowry G V., Brown Jr. GE. 2012. Environmental Transformations of Silver Nanoparticles : Impact on Stability and Toxicity. Environ Sci Technol., 46: 6900-6914 DOI: 10.10:6900-6914.

Levard C, Mitra S, Yang T, Jew AD, Badireddy AR, Lowry G V., Brown GE. 2013. Effect of Chloride on the Dissolution Rate of Silver Nanoparticles and Toxicity to E. coli. Environ Sci Technol [Internet]. [cited 2017 Sep 26]; 47:5738-5745. Available from: http://pubs.acs.org/doi/abs/10.1021/es400396f

Linsinger TPJ, Peters R, Weigel S. 2014. International interlaboratory study for sizing and quantification of Ag nanoparticles in food simulants by single-particle ICPMS. Anal Bioanal Chem [Internet]. 406:3835-3843. Available from: http://link.springer.com/10.1007/s00216-013-7559-9

Liu J, Hurt RH. 2010. Ion release kinetics and particle persistence in aqueous nano silver colloids. Environ Sci Technol. 44:2169-2175.

Mackevica A, Olsson ME, Hansen SF. 2016. Silver nanoparticle release from commercially available plastic food containers into food simulants. J Nanoparticle Res. 18:1-11.

Montaño MD, Olesik JW, Barber AG, Challis K, Ranville JF. 2016. Single Particle ICP-MS: Advances toward routine analysis of nanomaterials. Anal Bioanal Chem [Internet]. 408:5053-5074. Available from:

http://link.springer.com/10.1007/s00216-016-9676-8

Noonan GO, Whelton AJ, Carlander D, Duncan T V. 2014. Measurement Methods to Evaluate Engineered Nanomaterial Release from Food Contact Materials. Compr Rev Food Sci Food Saf [Internet]. [cited 2015 Aug 21]; 13:679-692. Available from: http://doi.wiley.com/10.1111/1541-4337.12079

Ntim SA, Thomas TA, Begley TH, Noonan GO. 2015. Characterisation and potential migration of silver nanoparticles from commercially available polymeric food contact materials. Food Addit Contam Part A [Internet]. 32:1003-1011. Available from: http://www.tandfonline.com/doi/full/10.1080/19440049.2015.1029994

Ntim SA, Thomas TA, Noonan GO. 2016. Influence of aqueous food simulants on potential nanoparticle detection in migration studies involving nanoenabled food-contact substances. Food Addit Contam Part A [Internet]. 33:905-912. 
Available from: http://www.tandfonline.com/doi/full/10.1080/19440049.2016.1174506

Pace HE, Rogers NJ, Jarolimek C, Coleman VA, Gray EP, Higgins CP, Ranville JF. 2012. Single particle inductively coupled plasma-mass spectrometry: a performance evaluation and method comparison in the determination of nanoparticle size. Environ Sci Technol [Internet]. 46:12272-80. Available from: http://www.ncbi.nlm.nih.gov/pubmed/22780106

Ramos K, Gómez-Gómez MM, Cámara C, Ramos L. 2016. Silver Speciation and characterization of nanoparticles released from plastic food containers by single particle ICPMS. Talanta [Internet]. 151:83-90. Available from: http://dx.doi.org/10.1016/j.talanta.2015.12.071

Schwertfeger DM, Velicogna JR, Jesmer AH, Scroggins RP, Princz JI. 2016. Single Particle-Inductively Coupled Plasma Mass Spectroscopy Analysis of Metallic Nanoparticles in Environmental Samples with Large Dissolved Analyte Fractions. Anal Chem. 88:9908-9914.

Tiede K, Boxall ABA, Tear SP, Lewis J, David H, Hassellöv M. 2008. Detection and characterization of engineered nanoparticles in food and the environment. Food Addit Contam Part A [Internet]. [cited 2013 Nov 12]; 25:795-821. Available from: http://www.ncbi.nlm.nih.gov/pubmed/18569000

Tuoriniemi J, Cornelis G. 2012. Size Discrimination and Detection Capabilities of Single-Particle ICPMS for Environmental Analysis of Silver Nanoparticles. Anal Chem. 84:3965-3972.

Tuoriniemi J, Cornelis G, Hassellöv M. 2015. A new peak recognition algorithm for detection of ultra-small nanoparticles by single particle ICP-MS using rapid time resolved data acquisition on a sector-field mass spectrometer. J Anal At Spectrom [Internet]. 30:1723-1729. Available from: http://xlink.rsc.org/?DOI=C5JA00113G

USFDA. 2016. Sodium in Your Diet: Use the Nutrition Facts Label and Reduce Your Intake [Internet]. [place unknown]. Available from: https://www.fda.gov/food/ingredientspackaginglabeling/labelingnutrition/ucm315393.htm

Utembe W, Potgieter K, Stefaniak AB, Gulumian M. 2015. Dissolution and biodurability: Important parameters needed for risk assessment of nanomaterials. Part Fibre Toxicol [Internet]. 12:1-12. Available from:

http://www.particleandfibretoxicology.com/content/12/1/11

Yu S, Yin Y, Chao J, Shen M, Liu J. 2014. Highly Dynamic PVP-Coated Silver Nanoparticles in Aquatic Environments: Chemical and Morphology Change Induced by Oxidation of Ag-0 and Reduction of Ag+. Environ Sci Technol. 48:403411.

Zhang W, Yao Y, Sullivan N, Chen Y. 2011. Modeling the primary size effects of citrate-coated silver nanoparticles on their ion release kinetics. Environ Sci Technol. 45:4422-4428. 

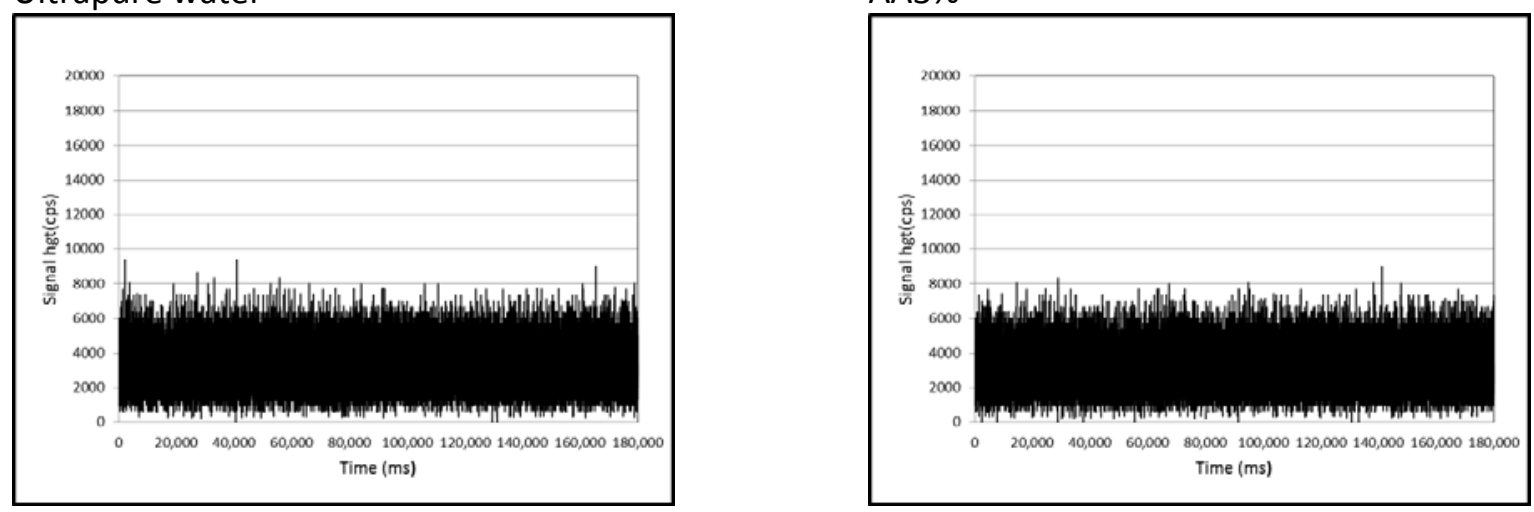

\section{E10\%}

\section{E20\%}

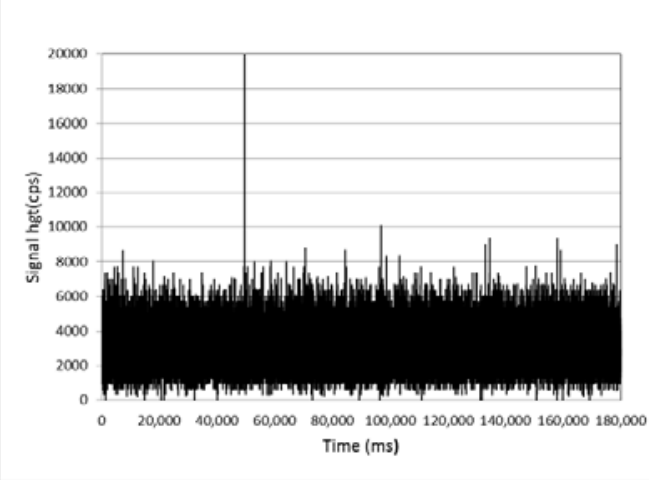

\section{$\mathrm{E} 50 \%$}
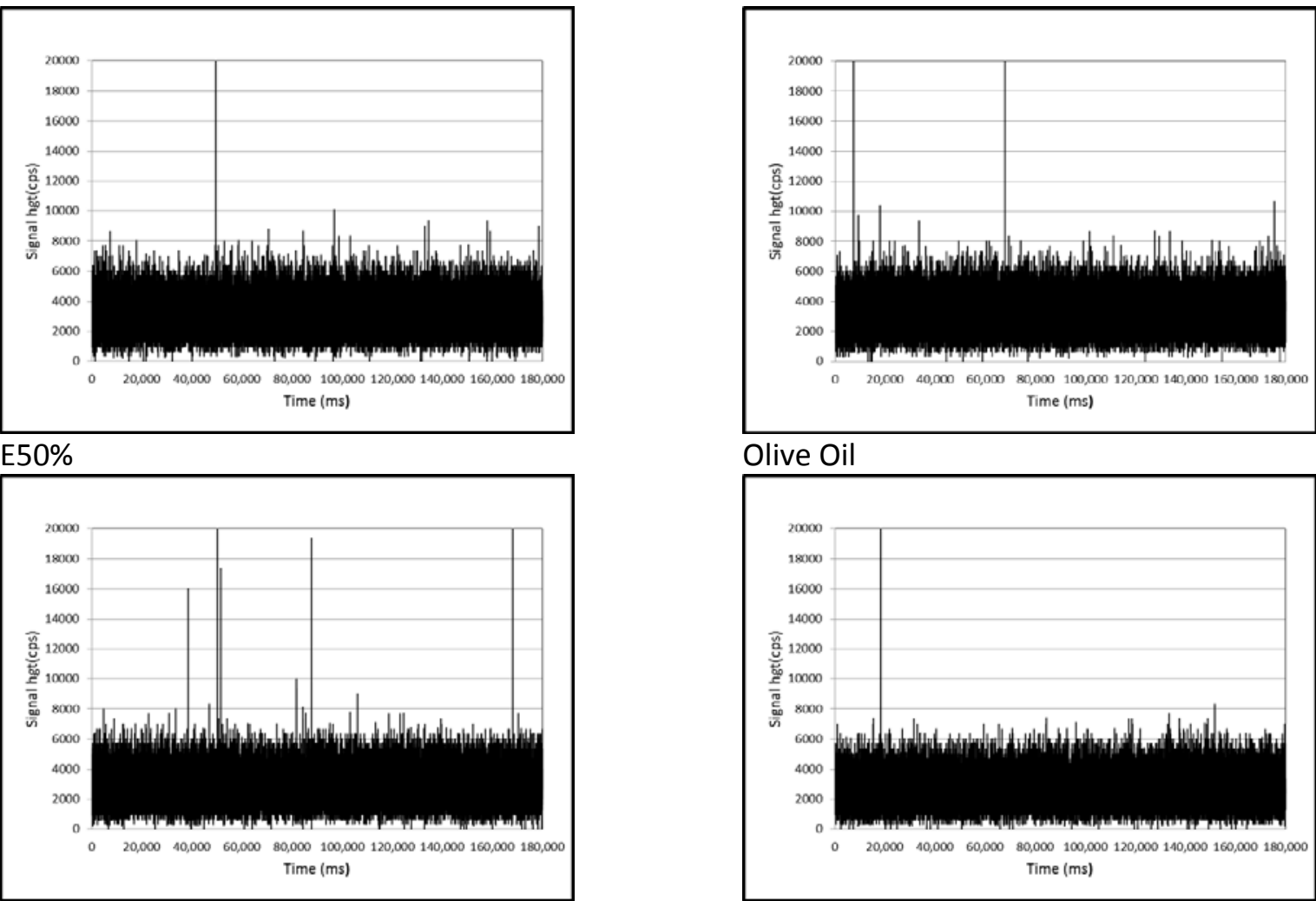

\section{Olive Oil}

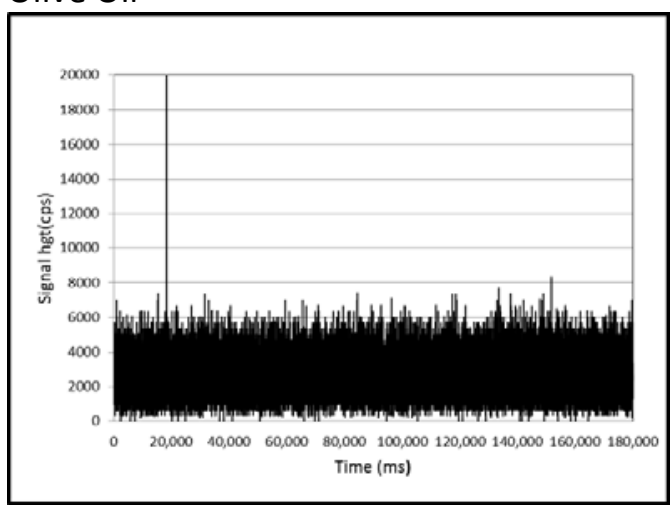

Low fat milk

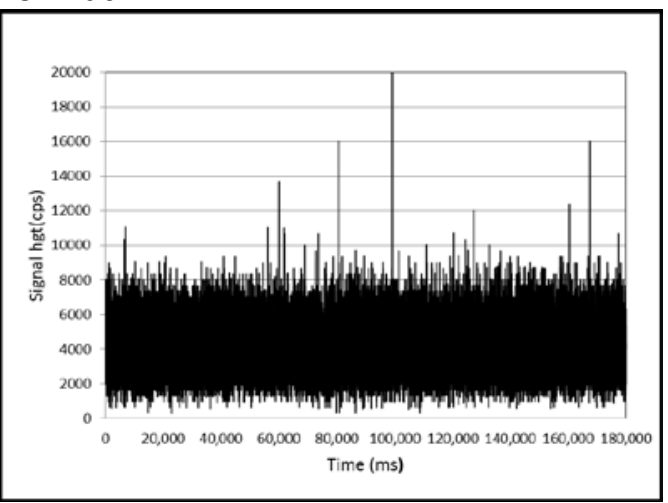

Supplementary Figure 1: Time-resolved spICP-MS signals of different food simulants and low fat cow milk spiked with $20 \mu \mathrm{g} \mathrm{L}^{-1} \mathrm{Ag}$ ions and incubated at $40^{\circ} \mathrm{C}$ for 10 days for food simulants and at $4^{\circ} \mathrm{C}$ for 5 days for milk sample. All samples were diluted 1000-times to a concentration of $20 \mathrm{ng} \mathrm{L}^{-1}$ before analysis. Up to 20 spikes/events during $3 \mathrm{~min}$ measurement were also detected in blank samples due to carry-over from previous measurement. 
Negative control (without silver)

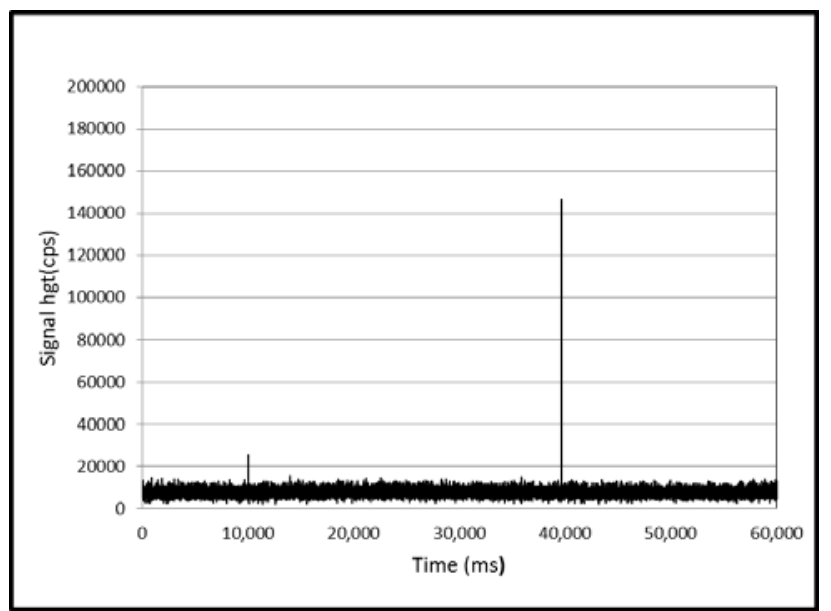

$200 \mu \mathrm{g} \mathrm{L}^{-1}$

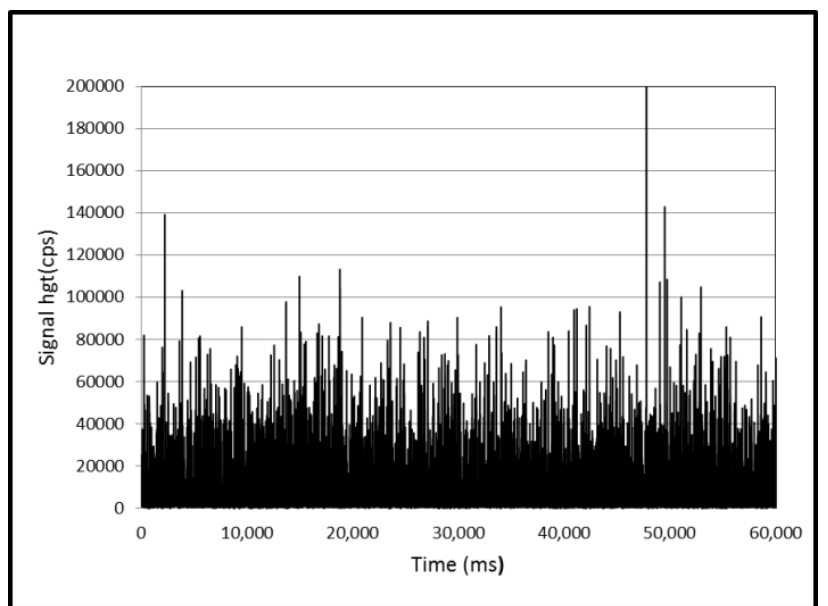

$43 \mathrm{mg} \mathrm{L}^{-1}$

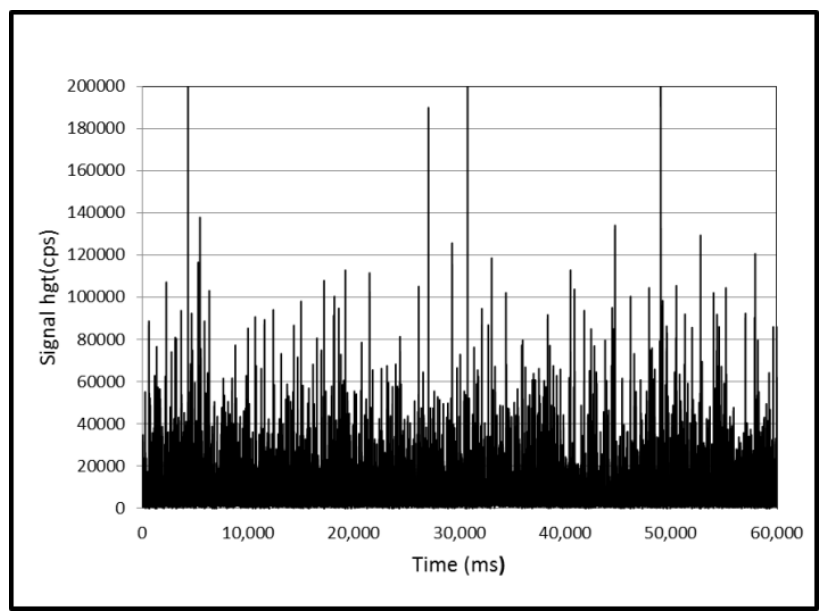

$20 \mu \mathrm{g} \mathrm{L}^{-1}$

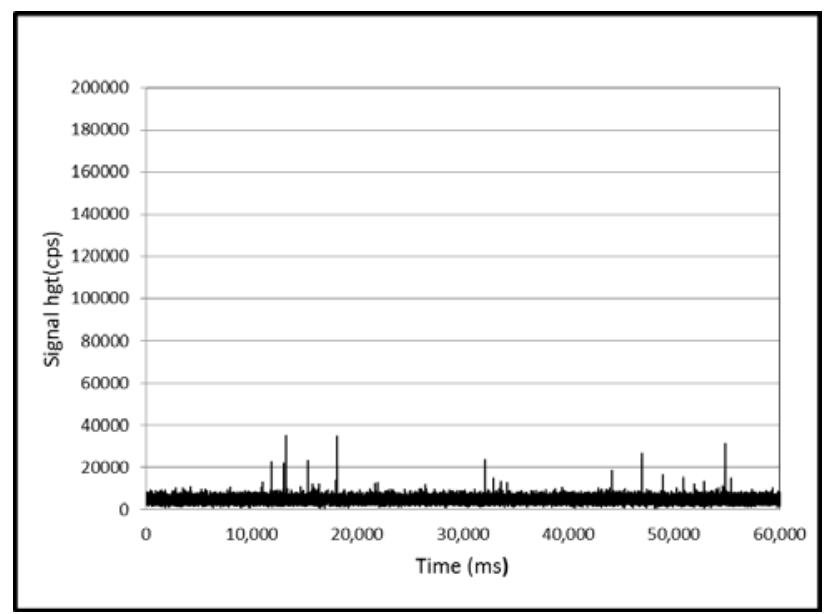

$10 \mathrm{mg} \mathrm{L}^{-1}$

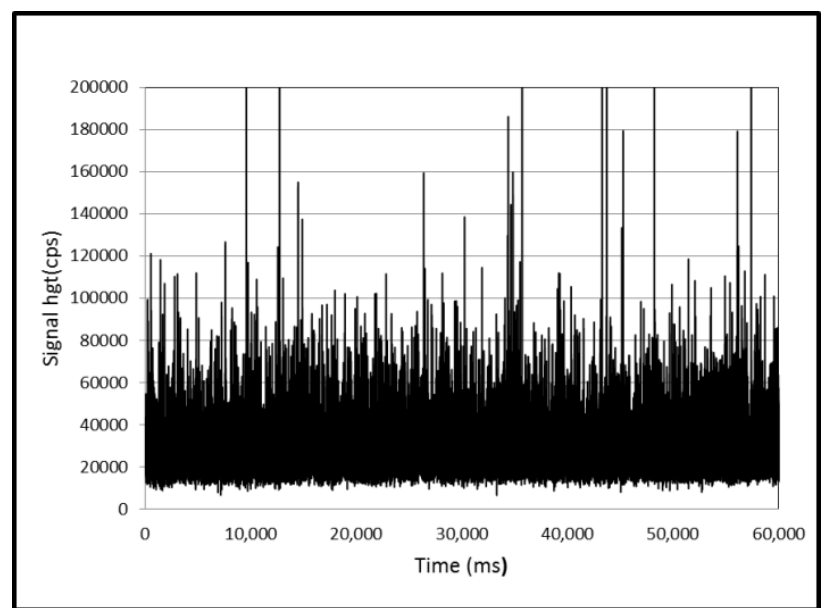

Positive control (20 $\mu \mathrm{L} \mathrm{L}^{-1}$ PEG-AgNPs)

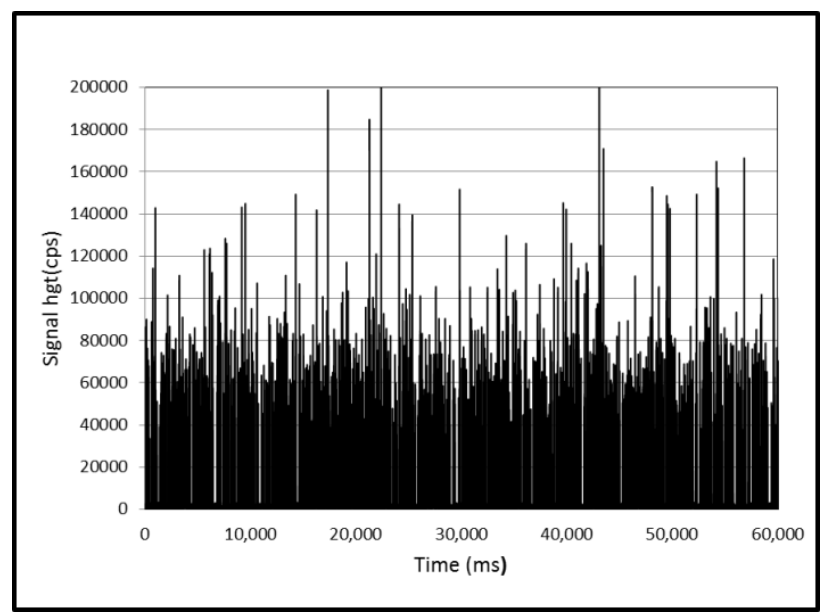

Supplementary Figure2: Time-resolved spICP-MS signals of solutions resulting from the reduction of silver nitrate in alkaline conditions. The Ag mass concentrations in the solutions after synthesis were $20 \mu \mathrm{g} L-1$, $200 \mu \mathrm{g} \mathrm{L}-1,10 \mathrm{mg} \mathrm{L}-1$ or $43 \mathrm{mg} \mathrm{L}-1$. All solutions were diluted to a concentration of $20 \mathrm{ng}$ L-1 before analysis. 
Supplementary Table A. Characteristics of the pristine AgNPs as provided by the supplier

\begin{tabular}{|c|c|c|}
\hline Items & PEG-AgNPs & Citrate-AgNPs \\
\hline Solvent & Milli-Q water & Aqueous $2 \mathrm{mM}$ citrate \\
\hline $\mathrm{pH}$ of solution & 5.6 & \begin{tabular}{|l|}
7.9 \\
\end{tabular} \\
\hline Particle surface & mPEG 5 kDa & Sodium citrate \\
\hline Diameter $^{a}$ & $41 \pm 4 \mathrm{~nm}$ & $40 \pm 4 \mathrm{~nm}$ \\
\hline Hydrodynamic diameter ${ }^{b}$ & $64 \mathrm{~nm}$ & $45 \mathrm{~nm}$ \\
\hline Surface area $^{a}$ & $13.8 \mathrm{~m}^{2} \mathrm{~g}^{-1}$ & $14.0{\mathrm{~m} 2 \mathrm{~g}^{-1}}^{-1}$ \\
\hline Maximum absorbance wavelength $\left(\lambda_{\max }\right)$ & $413 \mathrm{~nm}$ & $414 \mathrm{~nm}$ \\
\hline Mass concentration ${ }^{c}$ & $21 \mathrm{mg} \mathrm{L}^{-1}$ & $21 \mathrm{mg} \mathrm{L}^{-1}$ \\
\hline Particle concentration & $57 \times 10^{12}$ particles $\mathrm{L}^{-1}$ & $58 \times 10^{12}$ particles $\mathrm{L}^{-1}$ \\
\hline
\end{tabular}

${ }^{a}$ determined by transmission electron microscopy

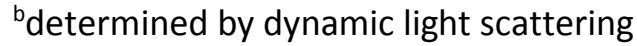

'determined by ICP-MS

Supplementary Table B: Number of detected particles, median particle size and minimum detectable particle size determined by spICP-MS of PEG-AgNPs in ultrapure water (MQ) and food simulants before and after 4 hours as well as 10 days incubation at $40^{\circ} \mathrm{C}(\mathrm{N}=2)$. The nominal spiking concentration was $20 \mu \mathrm{g} \mathrm{L}^{-1}$. The food simulants included 3\% v/v acetic acid (AA 3\%), 10\% v/v ethanol (E10\%), 20\% v/v ethanol (E20\%), $50 \% \mathrm{v} / \mathrm{v}$ ethanol (E50\%) and olive oil.

\begin{tabular}{|c|c|c|c|c|c|c|c|c|c|}
\hline \multirow[b]{2}{*}{$\begin{array}{l}\text { Food } \\
\text { simulants }\end{array}$} & \multicolumn{3}{|c|}{ Number of detected particles ${ }^{1}$} & \multicolumn{3}{|c|}{ Median particle size ${ }^{1}(\mathrm{~nm})$} & \multicolumn{3}{|c|}{$\begin{array}{l}\text { Minimum detectable particle size }{ }^{1} \\
(\mathrm{~nm})\end{array}$} \\
\hline & $\begin{array}{c}\text { Before } \\
\text { Incubation }\end{array}$ & $\begin{array}{c}\text { Short } \\
\text { Incubation } \\
\text { (4 hours at } \\
\left.40^{\circ} \mathrm{C}\right)\end{array}$ & $\begin{array}{c}\text { Long } \\
\text { Incubation } \\
(10 \text { days at } \\
\left.40^{\circ} \mathrm{C}\right)\end{array}$ & $\begin{array}{c}\text { Before } \\
\text { Incubation }\end{array}$ & $\begin{array}{c}\text { Short } \\
\text { Incubation } \\
\text { (4 hours at } \\
\left.40^{\circ} \mathrm{C}\right)\end{array}$ & $\begin{array}{c}\text { Long } \\
\text { Incubation } \\
(10 \text { days at } \\
\left.40^{\circ} \mathrm{C}\right)\end{array}$ & $\begin{array}{c}\text { Before } \\
\text { Incubation }\end{array}$ & $\begin{array}{c}\text { Short } \\
\text { Incubation } \\
\text { (4 hours at } \\
40^{\circ} \mathrm{C} \text { ) }\end{array}$ & $\begin{array}{c}\text { Long } \\
\text { Incubation } \\
(10 \text { days at } \\
\left.40^{\circ} \mathrm{C}\right)\end{array}$ \\
\hline $\begin{array}{l}\text { Ultrapure } \\
\text { water }\end{array}$ & $4658 \pm 212$ & $4369 \pm 32$ & $285 \pm 370$ & $31.1 \pm 0.4$ & $31.9 \pm 0.2$ & N/A & $17.6 \pm 0.0$ & $17.3 \pm 0.4$ & $19.8 \pm 0.7$ \\
\hline AA $3 \%$ & $4460 \pm 125$ & $2834 \pm 54$ & $10 \pm 7$ & $32.4 \pm 0.2$ & $29.8 \pm 0.0$ & N/A & $14.1 \pm 0.1$ & $15.9 \pm 0.0$ & $19.7 \pm 0.1$ \\
\hline $\mathrm{E} 10 \%$ & $6006 \pm 97$ & $5030 \pm 188$ & $105 \pm 74$ & $32.6 \pm 0.1$ & $31.3 \pm 0.1$ & N/A & $17.6 \pm 0.1$ & $16.2 \pm 0.1$ & $18.2 \pm 0.3$ \\
\hline E20\% & $4042 \pm 162$ & $4138 \pm 129$ & $301 \pm 23$ & $31.7 \pm 0.1$ & $31.9 \pm 0.1$ & N/A & $16.1 \pm 0.0$ & $15.4 \pm 0.4$ & $17.7 \pm 0.0$ \\
\hline$E 50 \%$ & $4355 \pm 32$ & $4733 \pm 707$ & $4045 \pm 226$ & $32.0 \pm 0.1$ & $32.1 \pm 0.1$ & $30.3 \pm 1.1$ & $15.4 \pm 0.3$ & $15.9 \pm 0.3$ & $17.3 \pm 0.1$ \\
\hline Olive Oil & $5463^{2}$ & $2285 \pm 142$ & $534 \pm 72$ & $32.1^{2}$ & $30.9 \pm 0.2$ & $26.6 \pm 0.1$ & $17.0^{2}$ & $17.1 \pm 0.3$ & $18.3 \pm 0.7$ \\
\hline
\end{tabular}

${ }^{1}$ results are presented as mean \pm standard deviation $(\mathrm{N}=2)$

${ }^{2}$ There was no replication 